RECENTD

FER 141997

OSTI

\title{
Ground Penetrating Radar and Direct Current Resistivity Evaluation of the Desiccation Test Cap
Savannah River Site
}

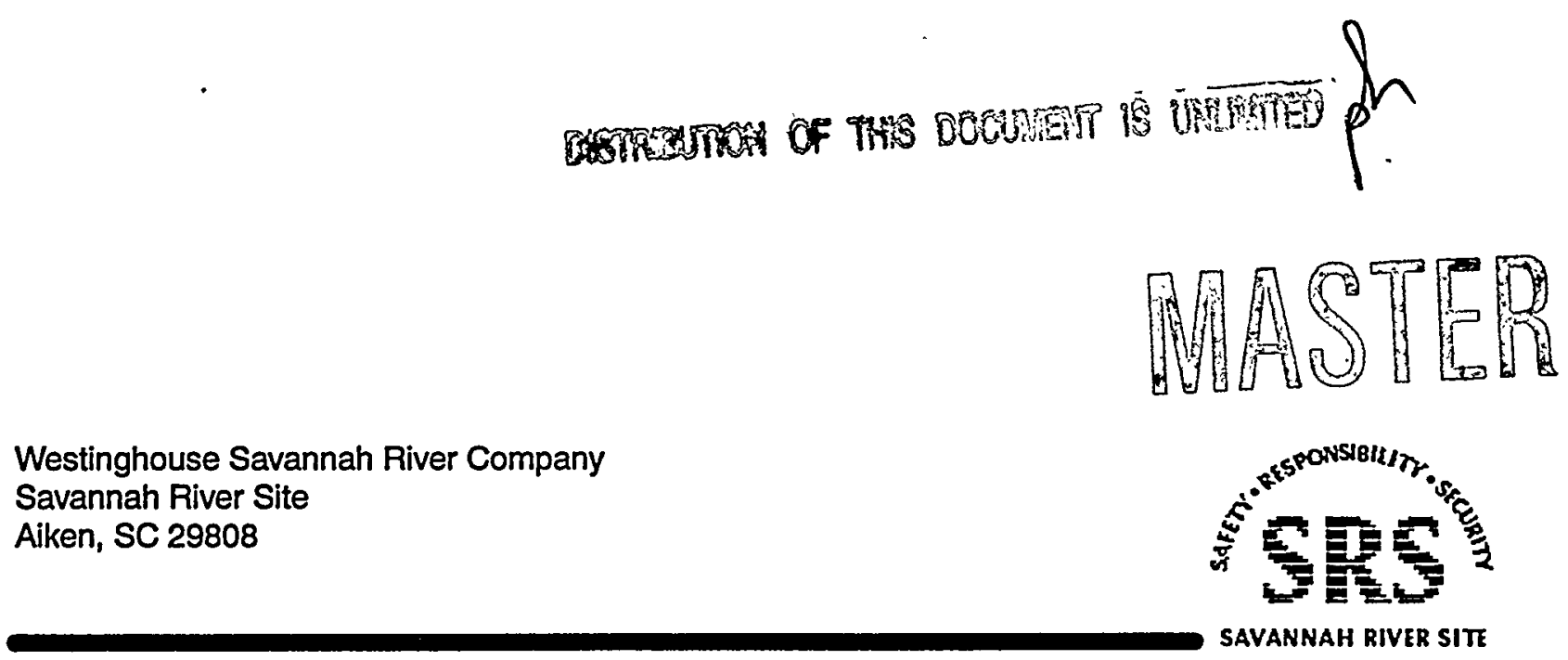

Prepared for the U.S. Department of Energy under contract no. DE-AC09-89SR18035 


\section{DISCLAIMER}

This report was prepared as an account of work sponsored by an agency of the United States Government. Neither the United States Government nor any agency thereof, nor any of their employees, makes any warranty, express or implied, or assumes any legal liability or responsibility for the accuracy, completeness, or usefulness of any information, apparatus, product, or process disclosed, or represents that its use would not infringe privately owned rights. Reference herein to any specific commercial product, process, or service by trade name, trademark, manufacturer, or otherwise does not necessarily constitute or imply its endorsement, recommendation, or favoring by the United States Government or any agency thereof. The views and opinions of authors expressed herein do not necessarily state or reflect those of the United States Government or any agency thereof.

This report has been reproduced directly from the best available copy.

Available to DOE and DOE contractors from the Office of Scientific and Technical Information, P.O. Box 62, Oak Ridge, TN 37831; prices available from (615) 576-8401.

Available to the public from the National Technical Information Service, U.S. Department of Commerce; 5285 Port Royal Road, Springfield, VA 22161. 


\title{
Ground Penetrating Radar and Direct Current Resistivity Evaluation of the Desiccation Test Cap, Savannah River Site ${ }^{(\mathrm{U})}$
}

\author{
D. E. Wyatt \\ R. J. Cumbest \\ Site Geotechnical Services
}

Prepared for the U.S. Department of Energy under contract no. DE-AC09-89SR18035 


\section{DISCLAIMER}

Portions of this document may be illegible in electronic image products. Images are produced from the best available original document. 


\section{Contents}

INTRODUCTION

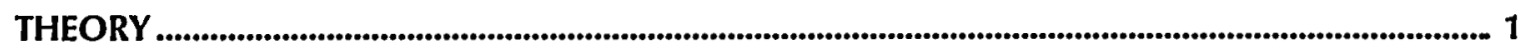

METHODOLOGY

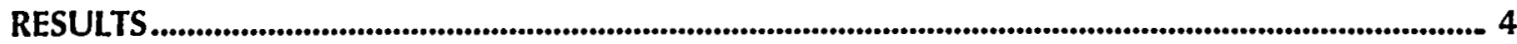

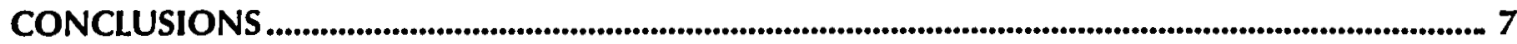

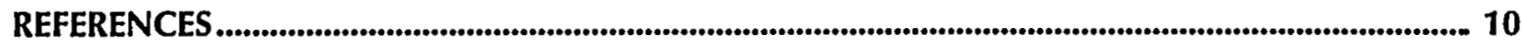

APPENDICES

Appendix A. Resistivity Data and Field Notes........................................................................................ 11

Appendix B. Microseeps $₫$ Ground Penetrating Radar Data and Report........................................... 16

\section{LIST OF FIGURES}

1. Plan View of the Desiccation Test Cap Site ......................................................................................2

2. Results of Resistivity Survey Line 1 ........................................................................................................................... 5

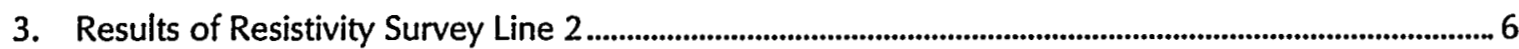

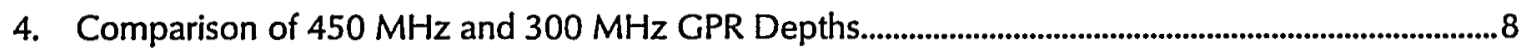

5. GPR Comparison of Parallel versus Perpendicular Array ........................................................................... 9 


\section{INTRODUCTION}

The Savannah River Site (SRS) has a variety of waste units that may be temporarily or permanently stabilized by closure using an impermeable cover to prevent groundwater infiltration. The placement of an engineered kaolin clay layer over a waste unit is an accepted and economical technique for providing an impermeable cover but the long term stability and integrity of the clay in non-arid conditions is unknown. Numerous factors may affect clay and cap integrity, including desiccation, erosion, bioturbation, physical damage and structural failure.

A simulated kaolin cap has been constructed at the SRS adjacent to the Burial Ground Complex (Figure 1). The cap is designed to evaluate the effects of desiccation on clay integrity, therefore half of the cap is covered with native soil to prevent drying, while the remainder of the cap is exposed. Infiltrometers are installed within a portion of the covered cap and the remainder of the area is available for additional studies.

Measurements of the continuing impermeability of a clay cap are difficult because intrusive techniques may locally compromise the structure. Point measurements made to evaluate clay integrity, such as those from grid sampling or coring and made through a soil cover, may miss cracks, joints or fissures, and may not allow for mapping of the lateral extent of elongate features. Because of these problems, a non-invasive technique is needed to map clay integrity, below a soil or vegetation cover, which is capable of moderate to rapid investigation speeds.

Two non-intrusive geophysical techniques, direct current resistivity and ground penetrating radar (GPR), have been successful at the SRS in geologically mapping shallow subsurface clay layers. The applicability of each technique in detecting the clay layer in the desiccation test cap and associated anomalies was investigated.

\section{THEORY}

\begin{abstract}
Surface resistivity profiling is a well known and understood geophysical tool using an induced direct electrical current to measure the apparent resistivity of subsurface sediments. In the Wenner Array method, current and potential electrodes are equally spaced with the potential electrodes in the center of the array and the current electrodes on the outside of the array. A reversing DC current is applied to the outer electrodes which sets up an electric field in the subsurface.
\end{abstract}

The voltages created at the potential electrodes are measured and the apparent resistivity of the subsurface material through which the current was transferred is determined using the standard electrical equation $V=I / R$. The depth of investigation is related to the spacing of the electrodes with larger spacings investigating deeper depths. For additional theory on the Wenner Array technique, see Ward, 1990 and Roy and Apparao, 1971.

The Wenner method was chosen because Ward (1990) suggests the technique has a high signal to noise ratio with a good resolution of horizontal layers, has a moderate rating for the resolution of steeply dipping structures (cracks) and is only moderately sensitive to surface inhomogeneities.

The Ground Penetrating Radar technique was chosen because of the very high resolution detection capabilities in the shallow subsurface and because of a broad range of experience with GPR signal responses at the SRS. GPR uses microwave range radar frequencies reflecting from subsurface changes in dielectric values to provide an 

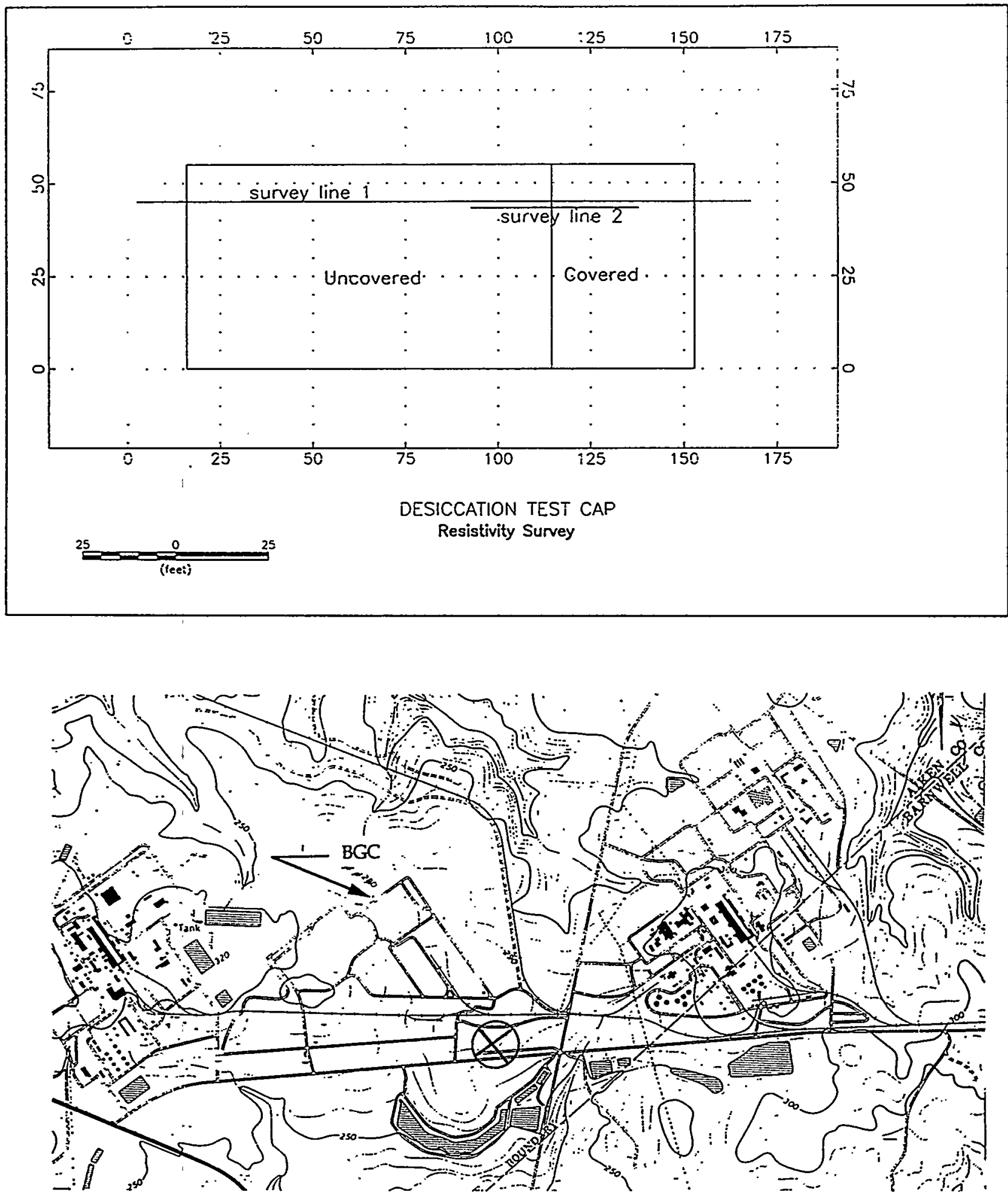

Figure 1. Plan view of the Desiccation Test Cap and survey lines. Resistivity data were acquired along Lines 1 and 2 and GPR data were acquired along Line 1. The Test Cap is located east of the Burial Ground Complex and along E Road. 
electrical image of the subsurface. Basic GPR theory is discussed in Moffat and Puskar (1976), Ulriksen (1982), Davis and Annan (1989), Annan et al. (1991), Annan and Cosway (1992), Fisher et al. (1992), and Wyatt et al. (1993). Techniques for the seismic style processing of GPR data are discussed in Fisher et al. (1992b) and Hu et al. (1992). The use of multiple antenna frequencies is discussed in Smith and Jol (1992). Data were acquired in one sampling day therefore the overall seasonal variation of moisture remained steady throughout the study and the variations noted in Roberts et al. (1991) are not thought to affect the data.

The GSSI $300 \mathrm{MHz}$ antenna configuration was chosen for two principal reasons; 1) this antenna configuration (and the acquisition system) is readily available and commonly used, and 2) the $300 \mathrm{MHz}$ frequency provides a shallower depth of investigation. The 450 MHz Pulse Ekko 1000 configuration was chosen because it is also readily available and commonly used while potentially providing shallower and higher resolution data than the $300 \mathrm{MHz}$ configuration. The ability of the Pulse Ekko system to acquire data in a CMP mode also allowed for a seismic style imaging of the shallow subsurface.

It should be noted that both the resistivity and GPR measurements of the Desiccation Test Cap assume that the kaolin section, as originally engineered, was uniform and homogeneous. Therefore, any heterogeneities will be detected as anomalies. If there are natural variations in the uniformity of the kaolin section then it may not be possible to distinguish naturally occurring anomalies from the desired anomalies due to desiccation cracking.

\section{METHODOLOGY}

The initial survey line was established crossing the test cap from west to east. A zero station was established 17 feet west and 10 feet south of the uncovered kaolin cap. Flagged stations were set every 1.67 feet $(0.51 \mathrm{~m})$ until the cap was crossed with the final station placed 15 feet east of the test cap at a station 170 feet $(51.8 \mathrm{~m})$ from the start for a total of 100 sampling stations. Along this transect, the full thickness of the desiccation test cap exposed kaolin layer was reached at 71 feet $(21.64 \mathrm{~m})$, the covered (native soils and geotextile fabric) at 115 feet $(35.05 \mathrm{~m})$ and the edge of the test cap at 155 feet $(47.2$ $m)$. This same transect was utilized for the GPR profiles. Figure 1 shows the transect line.

The Wenner data were acquired using an 'a' spacing of $1.67 \mathrm{ft}(0.51 \mathrm{~m})$. This ' $\mathrm{a}$ ' spacing will generate apparent resistivities from a depth of approximately 1 foot $(0.3 \mathrm{~m})$. An ABEM Terrameter ${ }^{\oplus}$ with stainless steel electrodes was used to acquire the data. No attempt was made to actually determine a subsurface geophysical resistivity section by inversion. However, the data were used to generate a field of subsurface resistivity.values to allow the graphical presentation of relative changes in subsurface conditions that may suggest cracking due to drying or structural failure. Terrameter ${ }^{\oplus}$ data were acquired using four cycles per sample with an input current of 0.5 milli-amperes. The data were reduced to apparent resistivities using the standard Wenner equation:

$$
\mathrm{R}_{\mathrm{a}}=2 \pi \mathrm{a} \mathrm{R}_{\mathrm{m}}
$$

where a equals the ' $a$ ' spacing of 1.67 feet, $R_{m}$ is the measured field resistivity and $R_{a}$ is the apparent true resistivity, in ohm-feet, of the subsurface material.

The $450 \mathrm{MHz}$ GPR data were acquired with Pulse Ekko $1000^{\oplus}$ system antenna configurations in parallel to direction of travel and perpendicular to direction of travel modes. The change in antenna orientation has been discussed as a method to evaluate high clay soils by preventing preferential polarization of clay particles by microwave induced currents. Additionally, data were acquired with the antenna arrays in contact and 
elevated from the ground surface. The use of antenna arrays elevated from the surface was an attempt to establish a clear ' $T_{0}$ ' time break to define a unique surface contact marker. Acquisition parameters for the $450 \mathrm{MHz}$ array are described in Appendix B.

The third GPR technique used the SIR System 10 in a single channel mode with a fixed $300 \mathrm{MHz}$ antenna. Data were acquired on the surface and in an elevated mode similar to the $450 \mathrm{MHz}$ data. Acquisition parameters are discussed in Appendix B.

Processing of the GPR was kept to a minimum and was designed to eliminate systematic noise while maximizing the geologic signal. The processing of GPR data is further discussed in Appendix B.

\section{RESULTS}

The results of resistivity survey lines 1 and 2 are shown on Figures 2 and 3 respectively. Field data from the resistivity profiles are included in Appendix A. Maintaining the assumption that the resistivity array is measuring a uniform distance below surface (approximately 0.5 to 1 foot or 0.15 to $0.3 \mathrm{~m}$ ) then an increase in resistivity is expected for the more impermeable clay layer (due to less interstitial water). Theoretically, if a discontinuity (open crack) exists between the potential electrodes (within the 1.67 foot or $0.51 \mathrm{~m}$ ) then the resistivity will increase to infinity. In reality, the area of the apparent resistivity measurement is larger than the area of most cracks, therefore, a discontinuity would have to be complete across the area of the apparent resistivity to become infinite. Because of this, a general increase in resistivity above a predetermined level may suggest that discontinuous cracking is present. However, this increase may be caused by zones of drier clay and not be uniquely interpretable.

Within the full thickness of the uncovered test cap clay cover (refer to Figure 1) the average resistivity is approximately 1600 to $1700 \mathrm{ohm}$ feet. This resistivity is apparently higher than the local soils, which is anticipated. Visual observation of the exposed kaolin demonstrated numerous desiccation cracks, similar to mud cracks, and a visible moisture profile was observable along the walls of the larger cracks. The clay had a higher moisture content a few centimeters below the surface but no cracks were observed to completely breach the clay (this was difficult to observe).

The covered portion of the clay cap exhibited a much higher resistivity probably due to less moisture below the plastic sheeting separating the cover material from the clay. Apparent resistivity values approached infinity for the western portion of the covered cap but it was not possible to distinguish whether this was from discontinuities or dryness in the clays. The eastern portion of the covered cap exhibited lower resistivities suggesting that more moisture was present beneath the soil cover and plastic. It was not possible to distinguish whether this was caused by more moisture in the clay beneath unobservable tears in the plastic or from a continuous clay layer with no discontinuities.

A second resistivity transect (Line 2) across the uncovered-to-covered interval was acquired one ' $a$ ' spacing south of the original transect (Line 1) in an attempt to verify the very high resistivity anomaly (refer to Figure 2). The results of this transect are shown on Figure 3. The average apparent resistivity is similar (approximately $1700 \mathrm{ohm}$ feet) to Line 1 and the very high anomaly also appears to be present but shifted eastward. As with Line 1, there is a pronounced increase in resistivity under the soil and plastic cover possibly suggesting drier kaolin. The presence or absence of discontinuities or cracks is not discernible from this data and no definitive cause for the eastward shift could be determined. Since a definitive cause for the eastward shift in the data was not observable in the field, no additional transect lines were considered. 


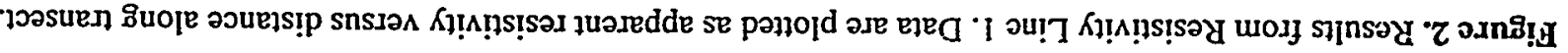

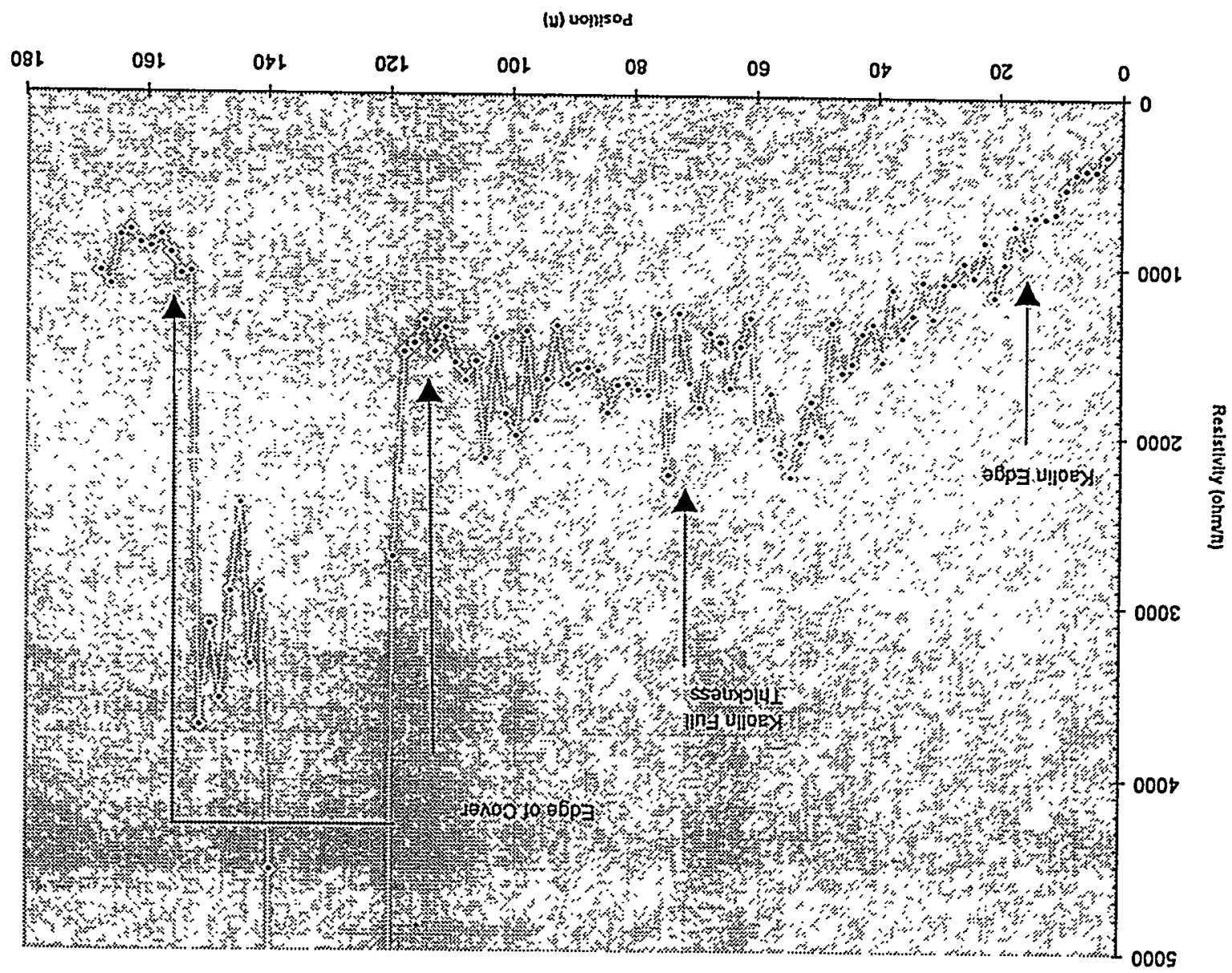




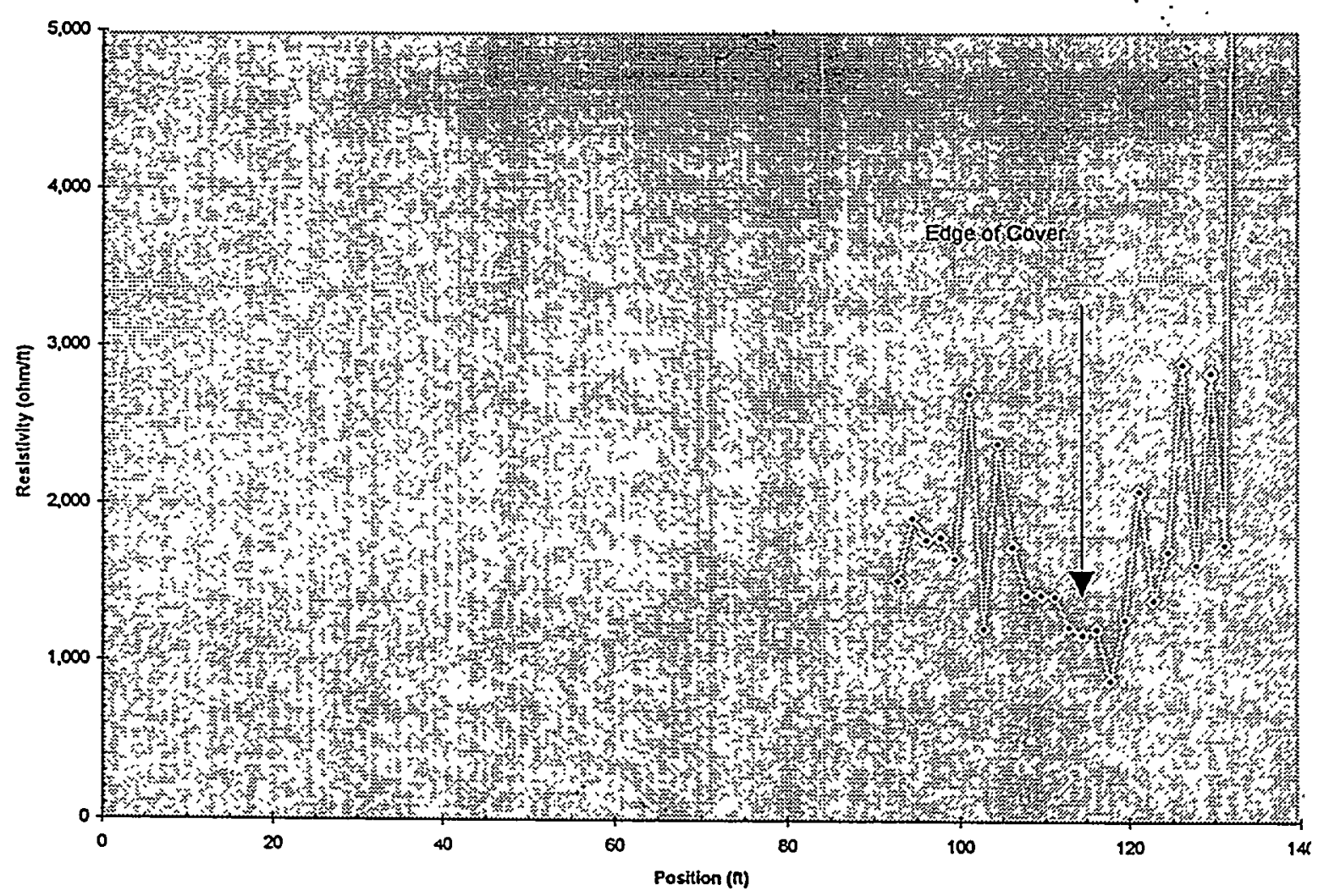

Figure 3. Results of Resistivity Line 2. Data are plotted as apparent resistivity versus distance along transect. 
The results of the GPR surveys are mixed. As expected, the $300 \mathrm{MHz}$ data images deeper zones but with less resolution than the $450 \mathrm{MHz}$ data. The $300 \mathrm{MHz}$ array images interpretable data to approximately $50 \mathrm{~ns}(6-7$ feet or $2 \mathrm{~m})$ while the $450 \mathrm{MHz}$ array images to approximately $30 \mathrm{~ns}(4-5$ feet or $1.5 \mathrm{~m}$ ) (Figure 4). The overall configuration of the subsurface is similar between the two systems and frequencies but the GSSI ${ }^{\otimes}$ data (refer to Appendix B figures 19 and 20) is "ringier" or has a lower signal to noise ratio than the Pulse Ekko $1000^{\otimes}$. Both frequency systems and antenna arrays were adequate to image the shallow clays within the test cap area. The inclined reflectors present on all sections (reference the Appendix B figures) are caused by the construction fill and sloping of the test cap which is gradual on the west and more abrupt on the east. Processing of the GPR data is discussed in Appendix B.

The response of the parallel versus perpendicular antenna arrays demonstrated a pronounced difference. The perpendicular array provides much better resolution with less signal noise suggesting a better couple with the subsurface and possibly less polarization. (Figure 5). The signal noise on the parallel array has the appearance of "wow" or ringing throughout the data suggesting that the processing required to eliminate the "wow" would eliminate the data as well. The spikes on the signal strength graphs at $t_{00}, t_{12}$ and $t_{24}$ (nanoseconds) suggest that the "wow" has a periodicity of 12 ns ringing through the data while no such spikes are seen on the perpendicular graph. The presence of the clay beneath the cover is generally observable as a reflection package bounded on the top and bottom by a low amplitude reflections and with high amplitude internal reflections (Appendix B figure 2). A review of the data (note for example, figures 5,6 and 9, included in Appendix B) demonstrates that there are no observable signal responses that uniquely suggest cracking or clay breaching within the interpreted clay interval.

The above ground acquisition established a clear $t_{0}$ break, but lost too much energy due to scattering. Very little energy entered the subsurface allowing imaging to approximately 6 nanoseconds or less than one foot $(0.3 \mathrm{~m})$. The GPR signal was fully attenuated in the kaolin section, however, variations in attenuation and/or amplitude response within the clay (reference Appendix B figures 8 and 9 at depths of 8 to $10 \mathrm{~ns}$ ) may be indicative of discontinuities or changes in uniformity. Further work will be necessary to determine if these anomalies are variations in moisture, clay thickness or composition or are structural features such as cracks.

\section{CONCLUSIONS}

In order for resistivity and GPR data to be adequately interpreted, it would be necessary to measure an undisturbed kaolin section to establish baseline resistivity values. Also, a breached section should be measured to establish the ideal response to a 'crack' or fracture in the clay. The use of resistivity to detect "wet" versus "dry" clay is highly possible, suggesting that resistivity may be a method of choice for locating places where the soil cover or plastic liner overlying the clay cap is breached. Generally, the lack of control on conditions under the covered portion of the test cap prevented the interpretation of the resistivity data to distinguish natural variations (such as those that may be due to heterogeneities in the clay) versus those that might be caused by cracks.

The results of the elevated ground penetrating radar surveys suggest that this technique may have promise as a "crack" detector. The $450 \mathrm{MHz}$ GPR perpendicular array generated higher resolution data than the parallel array. The reasons for this will require a dedicated investigation but are probably related to orientation/anisotropy of the clay grains as deposited or may relate to preferential polarization and signal absorption based on the GPR microwave field orientation. The use of higher frequency GPR antenna configurations, possibly in the $\mathrm{GHz}$ range, used on the surface may detect small scale discontinuities in the kaolin. The use of $450 \mathrm{MHz}$ or similar antenna systems, in an elevated mode so that the signal is attenuated within the zone of interest, may also be useful. 


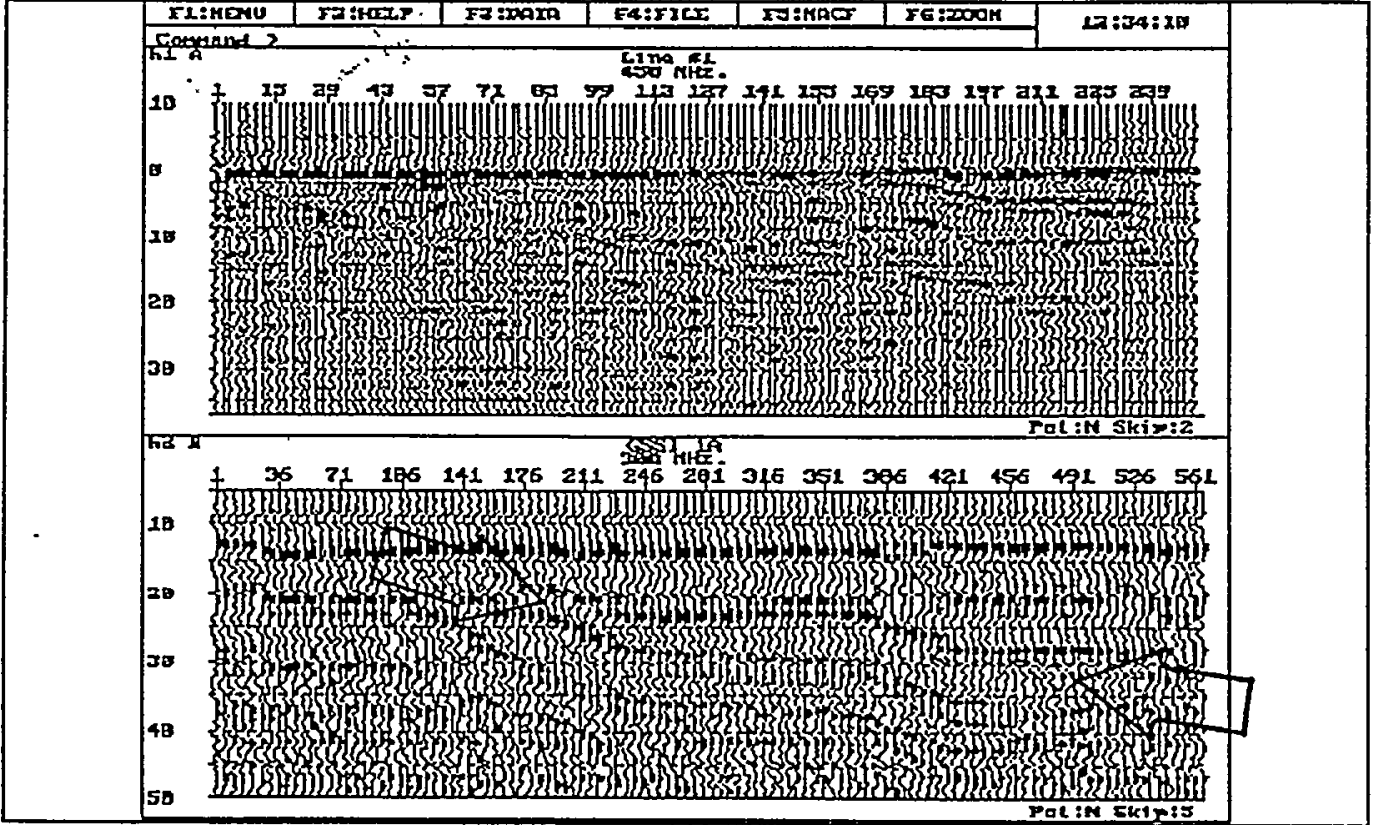

Comparison of Sensors \& Software $450 \mathrm{MHz}$. antenna and GSSI $300 \mathrm{MHz}$. antenna. Top S\&S, bottom GSSI.

Figure 4. Comparison of $450 \mathrm{MHz}$ data to $300 \mathrm{MHz}$ data, depth of investigation. The highlighted zone is the kaolin cap. 


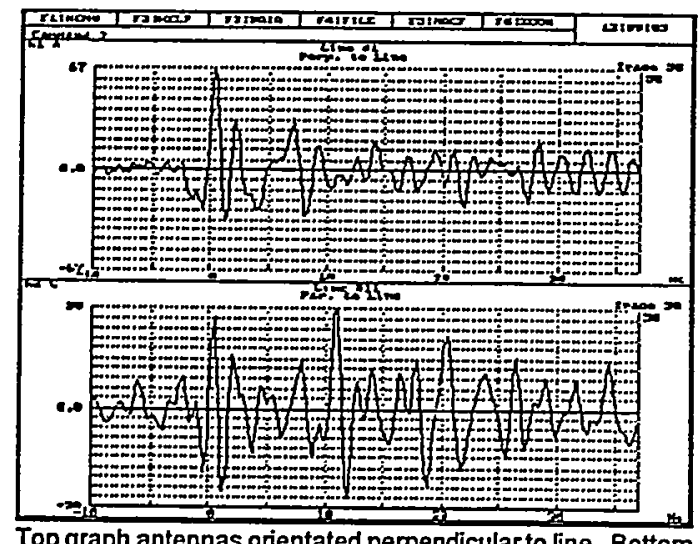

Top graph antennas orientated perpendicular to line. Bottom graph antennas orientated parallel to line.

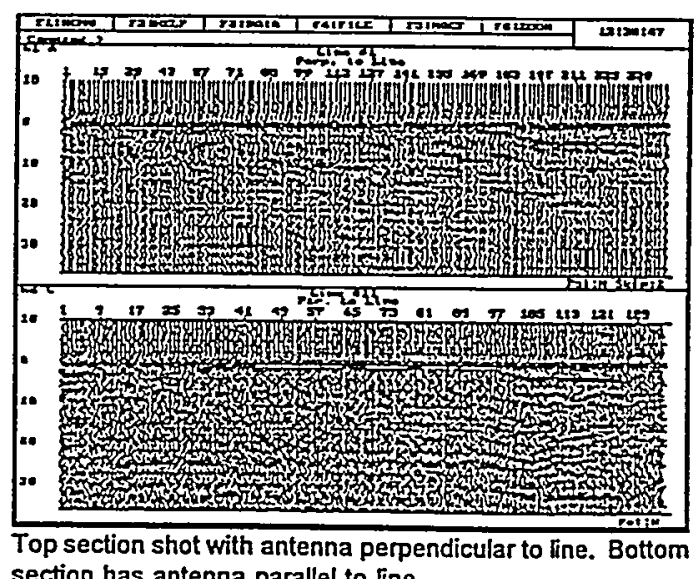

section has antenna parallel to ine.

Figure 5. GPR response comparison of parallel versus perpendicular arrays. The signal to noise ratio of the data in the top figures suggest a better coupling of the perpendicular oriented GPR signal with the
subsurface. 
Annan, A. P. and S. W. Cosway, 1992, "Ground Penetrating Radar Survey Design," Proceedings of the Symposium on the Application of Geophysics to Engineering and Environmental Problems, Vol. 2, Oakbrook, IL.

Annan, A. P., S. W. Cosway and J. D. Redman, 1991, "Water Table Detection with Ground Penetrating Radar," Expanded Abstracts, Vol. 1, pp. 494-495, Society of Exploration Geophysicists 61st Annual Meeting, Houston, TX.

Davis, J. L. and A. P. Annan, 1989, “Ground Penetrating Radar for High Resolution Mapping of Soil and Rock Stratigraphy," Geophysical Prospecting, Vol. 37, pp. 531551.

Fisher, E., G. A. McMechan, and A. P. Annan, 1992, "Acquisition and Processing of Wide-Aperture Ground Penetrating Radar Data," Geophysics, Vol. 57, No. 3, p. 495 504.

Fisher, E., G. A. McMechan, A. P. Annan, and S. W. Cosway, 1992, "Examples of Reverse-Time Migration of Single-Channel Ground Penetrating Radar Profiles," Geophysics, Vol. 57, No. 4, pp. 577-586.

Hu, L. Z., M. Ramaswamy, and B. McCormick, 1992, "Delineate Subsurface Structures with Ground Penetrating Radar," Houston Advanced Research Center Report, p. 16.

Moffat, D. L. and R. J. Puskar, 1976, “A Subsurface Electromagnetic Pulse Radar,” Geophysics. Vol. 41, No. 6, pp. 506-518.

Roberts, R., J. L. Daniels, and M. Vendl, 1991, "Seasonal Variations and Ground Penetrating Radar Data Repeatability," Expanded Abstracts, Vol. 1, pp. 486- 489, Society of Exploration Geophysicists 61st Annual Meeting, Houston, TX.

Roy, A. and A. Apparao, 1971, "Depth of Investigation in Direct Current Methods," Geophysics, Vol. 36, No. 5, pp. 943-959.

Smith, D. G. and H. M. Jol, 1992, "Ground Penetrating Radar Investigation of a Lake Bonneville Delta,” Provo Level, Brigham City, UT, Geology, Vol. 20, pp. 10831086.

Ulriksen, C. P. F., 1982, “Application of Impulse Radar to Civil Engineering,” Lund University of Technology, p.179.

Ward, S. H., 1990, "Resistivity and Induced Polarization Methods," Geotechnical and Environmental Geophysics, Vol. 1, S. H. Ward ed., pp. 147-189.

Wyatt, D. E., R. V. Brodine, G. B. Sexton, and R. J. Pirkle, 1993, “Advancements in Environmental Applications of Ground Penetrating Radar, In: Whitfield, P., Convenor, Meeting the Challenge, Environmental Remediation Conference, Proceedings of the ER '93, Environmental Remediation Conference, October 24-29, 1993, Augusta, GA. 
WSRC-TR-96-0080, Rev 0

April 16, 1996
Ground Penetrating Radar and Direct Current Resistivity Evaluation of the Desiccation Test Cap, Savannah River Site(U)

\section{Appendix A}

\section{Resistivity Data and Field Notes}


This page intentionally left blank. 


\section{Test Cap Wenner Resistlulty Profile \#1 Operator:D. Wyatt}

Date: 9-1-95 Comments: 85 deg, ground dry with some moisture, partly cloudy

array spacing $=5$ feet, ' $a$ ' spacing $=1.67$ feet

\begin{tabular}{crrr} 
OBS $X$ & \multicolumn{2}{c}{$Y$} & \multicolumn{2}{c}{$Z$-measured } \\
\hline 1 & 2.51 & 45 & 31.6 \\
2 & 4.18 & 45 & 40.3 \\
3 & 5.85 & 45 & 39.8 \\
4 & 7.52 & 45 & 41.9 \\
5 & $9.19 \cdot$ & 45 & 50.6 \\
6 & 10.86 & 45 & 64.4 \\
7 & 12.53 & 45 & 67
\end{tabular}
Z-calc ohm/ft Notes

$\begin{array}{llll}8 & 14.20 & 45 & 66.3\end{array}$

$9 \quad 15.87 \quad 45$

83.7

$10 \quad 17.54 \quad 45$

$\begin{array}{lll}11 & 19.21 & 45\end{array}$

$12 \quad 20.88 \quad 45$

$\begin{array}{lll}13 & 22.55 & 45\end{array}$

$\begin{array}{lll}14 & 24.22 & 45\end{array}$

$\begin{array}{lll}15 & 25.89 & 45\end{array}$

$\begin{array}{lll}16 & 27.56 & 45\end{array}$

$\begin{array}{lll}17 & 29.23 & 45\end{array}$

$\begin{array}{lll}18 & 30.90 & 45\end{array}$

$\begin{array}{lll}19 & 32.57 & 45\end{array}$

$20 \quad 34.24 \quad 45$

$21 \quad 35.91 \quad 45$

$\begin{array}{lll}22 & 37.58 & 45\end{array}$

$\begin{array}{lll}23 & 39.25 & 45\end{array}$

$24 \quad 40.92 \quad 45$

$25 \quad 42.59 \cdot 45$

$\begin{array}{lll}26 & 44.26 & 45\end{array}$

$\begin{array}{lll}27 & 45.93 & 45\end{array}$

$\begin{array}{lll}28 & 47.60 & 45\end{array}$

$\begin{array}{lll}29 & 49.27 & 45\end{array}$

$\begin{array}{lll}30 & 50.94 & 45\end{array}$

$\begin{array}{lll}31 & 52.61 & 45\end{array}$

$32 \quad 54.28 \quad 45$

$33 \quad 55.95 \quad 45$

$34 \quad 57.62 \quad 45$

$\begin{array}{lll}35 & 59.29 & 45\end{array}$

$\begin{array}{lll}36 & 60.96 & 45\end{array}$

$\begin{array}{lll}37 & 62.63 & 45\end{array}$

92.7

111.2

80.5

100.3

92.3

103.8

104.1

123.7

102.9

122.1

134.6

107.3

148.2

127

$132.4^{\circ}$

149.2

154.4

126.5

190.3

171

194.2

214

200

166.6

192.4

124.2

140.1
332 use black wires for current, red for potential

423 arrive onsite 10:40 $A M$, begin survey 11:10AM

418 did not use reels

440 settings: 4 cycles, $5 \mathrm{~mA}$,

531 incremental profile, move one MN each time

676 start at $0 \mathrm{ft}, 17$ kaolin, full kaolin thickness@ $@ 1^{\prime}$

703 edge of cover \& plastic @115', ending edge of cover (to east) @ 155', end line@170'

696 all notes measured from center of potential electrodes

878 edge of kaolin

750
973 cracks $1-2 \mathrm{~mm}$

1,167

845

1,052 damp clay

968

1,089

1,092

1,298 wider dessication cracks up to 1 $\mathrm{cm}$

1,080

1,281

1,412

1,126

1,555

1,333

1,389

1,566

1,620

1,327 move spread

1,997

1,794

2,038

2,245 more polarization noted 2,099 more polarization noted 1,748 more polarization noted 2,019 more polarization noted 1,303 more polarization noied 1,470 


\begin{tabular}{|c|c|c|c|c|c|}
\hline 38 & 64.30 & 45 & & 164 & 1,721 \\
\hline 39 & 65.97 & 45 & & 138.1 & 1,449 \\
\hline 40 & 67.64 & 45 & & 132.8 & 1,393 \\
\hline 41 & 69.31 & 45 & & 174.9 & 1,835 \\
\hline 42 & 70.98 & 45 & & 161.2 & $\begin{array}{l}1,691 \text { edge of kaolin cap, west rope } \\
\text { edge from photo }\end{array}$ \\
\hline 43 & 72.65 & 45 & & 121.7 & 1,277 \\
\hline 44 & 74.32 & 45 & & 213 & 2,235 \\
\hline 45 & 75.99 & 45 & & 122 & 1,280 \\
\hline 46 & 77.66 & 45 & & .168 & 1,763 \\
\hline 47 & 79.33 & 45 & & $165.1^{\circ}$ & 1,732 more polarization noted \\
\hline 48 & 81.00 & 45 & & 161.8; & 1,698 more polarization rioted \\
\hline 49 & 82.67 & 45 & $\because$ & 162.4 & 1,704 more polarization noted \\
\hline 50 & 84.34 & 45 & & 178.2 & 1,870 \\
\hline 51 & 86.01 & 45 & & 154.2 & 1,618 \\
\hline 52 & 87.68 & 45 & - & 152.5 & 1,600 \\
\hline 53 & 89.35 & 45 &.$\cdot$ & 153.7 & 1,613 \\
\hline 54 & 91.02 & 45 & & 162 & 1,700 rope center of cap from photo \\
\hline 55 & 92.69 & 45 & & 129.1 & 1,355 \\
\hline 56 & 94.36 & 45 & & 159.5 & 1,674 move spread \\
\hline 57 & 96.03 & 45 & & 182.8 & 1,918 \\
\hline 58 & 97.70 & 45 & & 132.6 & 1,391 \\
\hline 59 & 99.37 & 45 & & 191.1 & 2,005 \\
\hline 60 & 101.04 & 45 & & 179 & 1,878 \\
\hline 61 & 102.71 & 45 & & 136 & 1,427 \\
\hline 62 & 104.38 & 45 & & 204 & 2,141 \\
\hline 63 & 106.05 & 45 & & 149.2 & 1,566 \\
\hline 64 & 107.72 & 45 & & 160.4 & 1,683 \\
\hline 65 & 109.39 & 45 & & 150.2 & 1,576 \\
\hline 66 & 111.06 & 4.5 & & 130.5 & 1,369 east rope edge \\
\hline 67 & 112.73 & 45 & & 143.9 & 1,510 \\
\hline 68 & 114.40 & 45 & & 126.1 & 1,323 east edge of plastic and cover \\
\hline 69 & 116.07 & 45 & & 139.3 & 1,462 \\
\hline 70 & 117.74 & 45 & & 144.2 & $\begin{array}{l}1,513 \text { current would not penetrate } \\
\text { platic, had to drive electrodes } \\
\text { below plastic }\end{array}$ \\
\hline 71 & 119.41 & 45 & & 259 & 2,718 \\
\hline 72 & 121.08 & 45 & & 1181 & 12,392 high polarization \\
\hline 73 & 122.75 & 45 & & 5470 & 57,396 \\
\hline 74 & 124.42 & 45 & , & 1002 & 10,514 \\
\hline 75 & 126.09 & 45 & & 952 & 9,989 \\
\hline 76 & 127.76 & 45 & & 2740 & 28,751 \\
\hline 77 & 129.43 & 45 & & 1532 & 16,075 \\
\hline 78 & 131.10 & 45 & & 1824 & 19,139 \\
\hline 79 & 132.77 & 45 & & 1633 & 17,135 \\
\hline 80 & 134.44 & 45 & & 1503 & 15,771 \\
\hline 81 & 136.11 & 45 & & 605 & 6,348 \\
\hline 82 & 137.78 & 45 & & 2110 & 22,140 \\
\hline 83 & 139.45 & 45 & & 432 & 4,533 move spread \\
\hline 84 & 141.12 & 45 & & 279 & 2,928 \\
\hline
\end{tabular}




\begin{tabular}{|c|c|c|c|c|}
\hline 85 & 142.79 & 45 & 319 & 3,347 \\
\hline 86 & 144.46 & 45 & 230 & 2,413 \\
\hline 87 & 146.13 & 45 & 279 & 2,928 \\
\hline 88 & 147.79 & 45 & 338 & 3,547 \\
\hline 89 & 149.46 & 45 & 297 & 3,116 \\
\hline 90 & 151.13 & 45 & 353 & 3,704 \\
\hline 91 & 152.80 & 45 & 99.9 & 1,048 edge of cap \\
\hline 92 & 154.47 & 45 & 101.2 & 1,062 \\
\hline 93 & 156.14 & 45 & 89.6 & 940 \\
\hline 94 & $157.81:$ & .45 & 79.6 & 835 \\
\hline 95 & 159.48 & $\therefore 45$ & 86.3 & 906 off of backfill \\
\hline 96. & 161.15 & 45 & 84.5 & 887 lots of weeds on electrodes \\
\hline 97 & 162.82 & 45 & 76.9 & 807 \\
\hline 98 & 164.49 & 45 & 80.1 & 840 \\
\hline 99 & 166.16 & 45 & 107.4 & 1,127 \\
\hline 100 & 167.83 & 45 & 99.8 & 1,047 end at $170^{\prime}$, time is $1 \mathrm{pm}$ \\
\hline 1 & 92.69 & 43.3 & 144.8 & $\begin{array}{l}1,519 \text { start at } 90^{\prime} \text {, end at } 140^{\circ} \text {, moved } \\
\text { south one MN spacing }\end{array}$ \\
\hline 2 & 94.36 & 43.3 & 182.2 & $\begin{array}{c}1,912 \text { stat at } 1 / 2 \text { distance rope across } \\
\text { exposed clay, start at } 1: 10 \mathrm{pm}\end{array}$ \\
\hline 3 & 96.03 & 43.3 & 169.3 & 1,776 \\
\hline 4 & 97.70 & 43.3 & 170.7 & 1,791 \\
\hline 5 & 99.37 & 43.3 & 158 & 1,658 \\
\hline 6 & 101.04 & 43.3 & 258 & 2,707 \\
\hline 7 & 102.71 & 43.3 & 116 & 1,217 \\
\hline 8 & 104.38 & 43.3 & 227 & 2,382 \\
\hline 9 & 106.05 & 43.3 & 165.2 & 1.733 \\
\hline 10 & 107.72 & 43.3 & 135.9 & 1,426 \\
\hline 11 & 109.39 & 43.3 & 136.2 & 1,429 \\
\hline 12 & 111.06 & 43.3 & 135.3 & 1,420 eastern rope for pix \\
\hline 13 & 112.73 & 43.3 & 116.8 & 1,226 \\
\hline 14 & 114.40 & 43.3 & 112.1 & 1,176 edge of plastic \\
\hline 15 & 116.07 & 43.3 & 115.6 & 1,213 \\
\hline 16 & 117.74 & 43.3 & 84.7 & 889 \\
\hline 17 & 119.41 & 43.3 & 121.6 & 1,276 \\
\hline 18 & 121.08 & 43.3 & 198.8 & 2,086 \\
\hline 19 & 122.75 & 43.3 & 133.2 & 1,398 polarization \\
\hline 20 & 124.42 & 43.3 & 162.3 & 1,703 \\
\hline 21 & 126.09 & 43.3 & 275 & 2,886 \\
\hline 22 & 127.76 & 43.3 & 154.5 & 1,621 \\
\hline 23 & 129.43 & 43.3 & 270 & 2,833 \\
\hline 24 & 131.10 & 43.3 & 166.5 & 1,747 \\
\hline 25 & 132.77 & 43.3 & 863 & 9,055 \\
\hline 26 & 134.44 & 43.3 & 1346 & 14,123 \\
\hline 27 & 136.11 & 43.3 & 1178 & 12,361 \\
\hline 28 & 137.78 & 43.3 & 1793 & 18,814 end at $1: 35 \mathrm{pm}$ \\
\hline
\end{tabular}




\section{Appendix B}

Microseeps® GPR Data and Report 
This page intentionally left blank. 
Final Report

GROUND PENETRATING RADAR INVESTIGATIONS

at the

\section{CLAY CAP TEST SITE}

SAVANNAH RIVER SITE

October, 1995

G.Boyd Sexton

Robert J. Pirkle

As a Part of

Proposal No. SOS140EC 


\section{EXECUTIVE SUMMARY}

A Ground Penetrating Radar (GPR) survey was executed on October 3, 1995 at the Clay Cap Test Site for the purpose of determining if high frequency radar signals could locate small fractures in the clay and if radar antenna orientation is critical in determination. The survey yielded good GPR data, however all planned antenna configurations could not be run due to inclement weather produced by hurricane Opal. 


\section{TABLE OF CONTENTS}

Executive Summary

List of Tables

iii

List of Figures iv

I. Introduction

1

II. Background and Observations

1

III. Acquisition and Processing Parameters 2

IV. Results

3

V. Conclusions

5

VI. Appendix I

GPR Field Logs

Field Sketch 


\section{LIST OF TABLES}

Table 1. Coordinates, Bearings, and Distances of GPR Lines

Table 2. Acquisition and Processing Parameters 
LIST OF FIGURES

CLAY CAP TEST SITE

Figure 1. GPR Line Location Map

Figure 2. Sample GPR Section With Illustrated Computerized Interpretation

Figure 3. Field Calibration Results Start and End

Figure 4. GPR Line \# 1 S\&S $450 \mathrm{MHz}$. On Ground Perpendicular to Line

Figure 5. GPR Line \# 2 S\&S $450 \mathrm{MHz}$. On Ground Perpendicular to Line

Figure 6. GPR Line \# 3 S\&S $450 \mathrm{MHz}$. Gain change, Same as \#1

Figure 7. GPR Line \# 4 S\&S $450 \mathrm{MHz}$. Gain change, Same as \#2

Figure 8. GPR Line \# 5 S\&S $450 \mathrm{MHz}$. 10-12" above Ground Same as \#3

Figure 9. GPR Line \# 6 S\&S $450 \mathrm{MHz}$. 10-12" above Ground Same as \#4

Figure 10. GPR Line \# 7 S\&S $450 \mathrm{MHz}$. Gain change, Same as \#3

Figure 11. GPR Line \# 8 S\&S $450 \mathrm{MHz}$. Gain change, Same as \#4

Figure 12. GPR Line \# 9 S\&S $450 \mathrm{MHz}$. 2" above Ground Gain 600 Perpendicular

Figure 13. GPR Line \# 10 S\&S $450 \mathrm{MHz}$. 2" above Ground Gain 600 Perpendicular

Figure 14. GPR Line \# $11 \mathrm{~S} \& S 450 \mathrm{MHz}$. On Ground Parallel to Line

Figure 15. GPR Line \# 12 S\&S $450 \mathrm{MHz}$. On Ground Parallel to Line

Figure 16. GPR Line \# 13 S\&S $450 \mathrm{MHz} .12$ " above Ground Perpendicular to Line

Figure 17. GPR Line \# 14 S\&S $450 \mathrm{MHz}$. 12" above Ground Perpendicular to Line

Figure 18. GPR Line \# 15 S\&S $450 \mathrm{MHz} .12$ " above Ground Parallel to Line

Figure 19. GPR Line \# 16 S\&S $450 \mathrm{MHz} .12$ " above Ground Parallel to Line 


\section{LIST OF FIGURES (con't.) \\ CLAY CAP TEST SITE}

Figure 20. GPR Line \# 1A GSSI Comparison with $300 \mathrm{MHz}$. antenna 50ns Range

Figure 21. GPR Line \# 2A GSSI Comparison with $300 \mathrm{MHz}$. antenna 50ns Range 


\section{INTRODUCTION}

A Ground Penetrating Radar (GPR) survey was run at the Clay Cap Test Site for the purpose of determining if desiccation cracks or fractures could be seen beneath the clay cap covering the test site and amount of penetration of the signal beneath the clay cover. Various antenna orientations were planned to be conducted to determine the polarizating effect of the radar signal. The Clay Cap Test Site had a resistivity survey conducted prior to the GPR survey. The flagged survey stakes which were used in the resistivity survey were used as starting and ending points during the GPR survey. The distance between the stakes was 165 feet. All GPR lines were run along the same line starting at 13 feet and ending at 161 feet. All GPR lines have vertical marks displayed on the sections indicating the points where the antennas crossed the rope grid used as reference points. Due to cable length the last few feet on either end of the line were not surveyed.

\section{BACKGROUND AND OBSERVATIONS}

The Clay Cap Test Site is due east of the Burial Ground and fronting Road "E". The area has various experimental and testing sites within a large expanse. This project area is one small area within other test sites. The Clay Cap Test Site is a miniature version of a trench with a clay cap that might be typical in the Burial Ground. The weather during field acquisition was warm and overcast. The evening of October 3 , rain started from hurricane Opal and continued for the next several days. Personnel on-site during data acquisition were Boyd Sexton and Mike Woodward of Microseeps. Randy Cumbest of WSRC was present during the initial phases of acquisition. 


\section{ACQUISITION AND PROCESSING PARAMETERS}

The equipment and software used in the acquisition and processing of the GPR data are listed on Table 2. Both the Sensors and Software Pulse Ekko 1000 and GSSI Sir 10 System were employed. The antennas with Sensors and Software 1000 were 225, 450 and $900 \mathrm{MHz}$. Due to weather conditions at the site only the S\&S $450 \mathrm{MHz}$. and GSSI $300 \mathrm{MHz}$. antenna were used. The survey wheel was not used with the S\&S system so each line has varying numbers of traces, but vertical ticks are placed where the rope boundaries were crossed.

Antenna orientation with the S\&S is described in the diagram below:
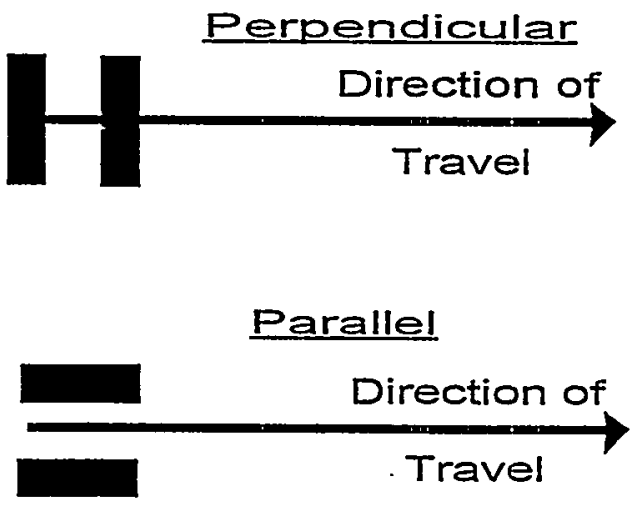

The final plots of all GPR data have the following processing routines applied.

\section{S\&S Data}

AGC

SPIKING DECON

AGC

FK FILTER

MEAN FILTER 


\title{
GSSI Data
}

\author{
SPIKING DECON \\ AGC \\ FK FILTER \\ MEAN FILTER
}

\section{RESULTS}

The results of the GPR surveys at Clay Cap Test Site are shown on Figures 4 22. A sample GPR section with labeled interpretive information is shown on Figure 2. Typical signatures of an air wave, ground surface and subsurface features are labeled so that similar anomalous areas on the actual lines presented on Figures $4-22$ can be easily recognized. The acquisition and processing information can be found on Table 2 .

The radar velocity in this area is 6-7 ns per foot.

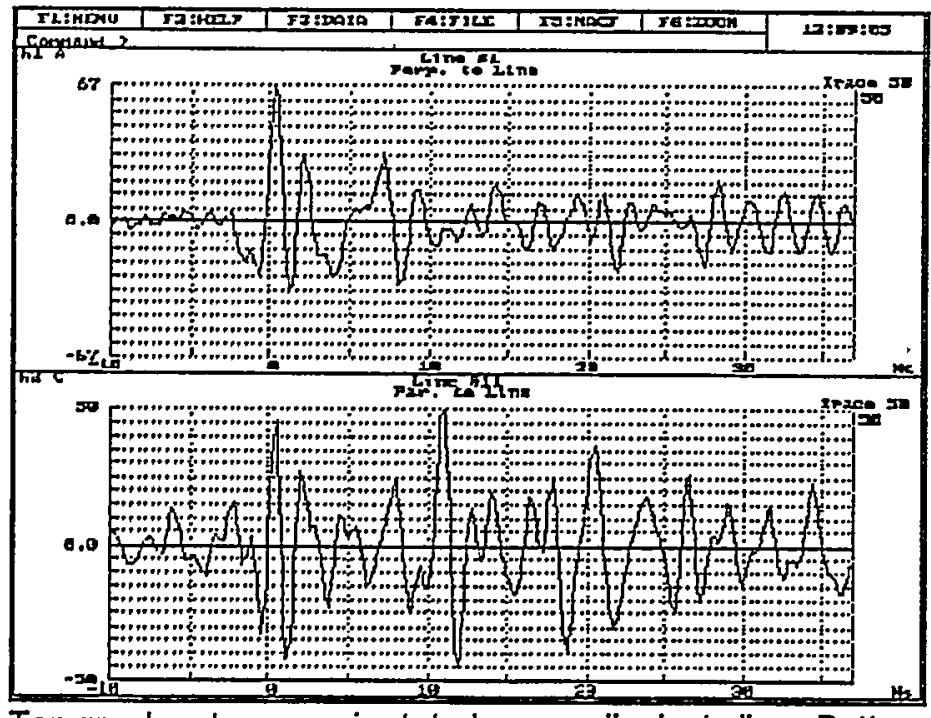

Top graph antennas orientated perpendicular to line. Bottom graph antennas orientated parallel to line.

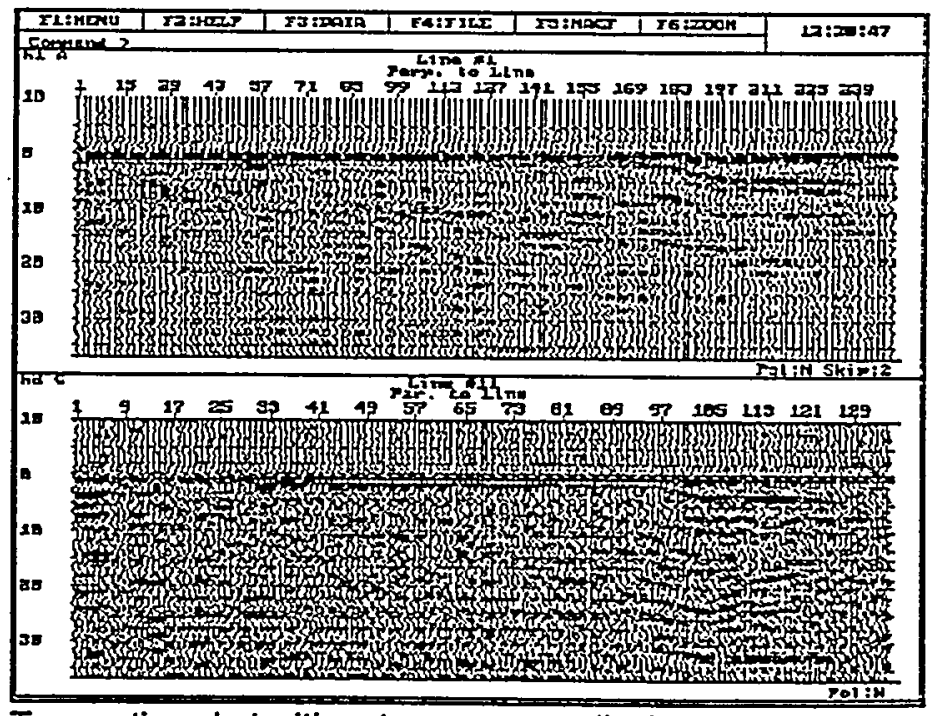

Top section shot with antenna perpendicular to line. Bottom section has antenna parallel to line. 
The Clay Cap Test Site was generally a good data area. The above plots compare the perpendicular versus parallel data acquired with the S\&S $450 \mathrm{MHz}$ antenna. Clearly the perpendicular antenna array has better definition than the parallel configuration. The parallel configuration appears to generate higher amplitude noise spikes as seen on the upper left graph.

"Air shooting" (with antennas off the ground) was tried on lines $5,6,9,10,13,14,15$ and 16. The purpose was to define the actual air/ground contact and hopefully see any indications of the desiccation fractures at the air/ground surface. This test had limited successs, possibly due to the high loss of energy through the air. As can be seen in these plots little energy is reflected from the subsurface.

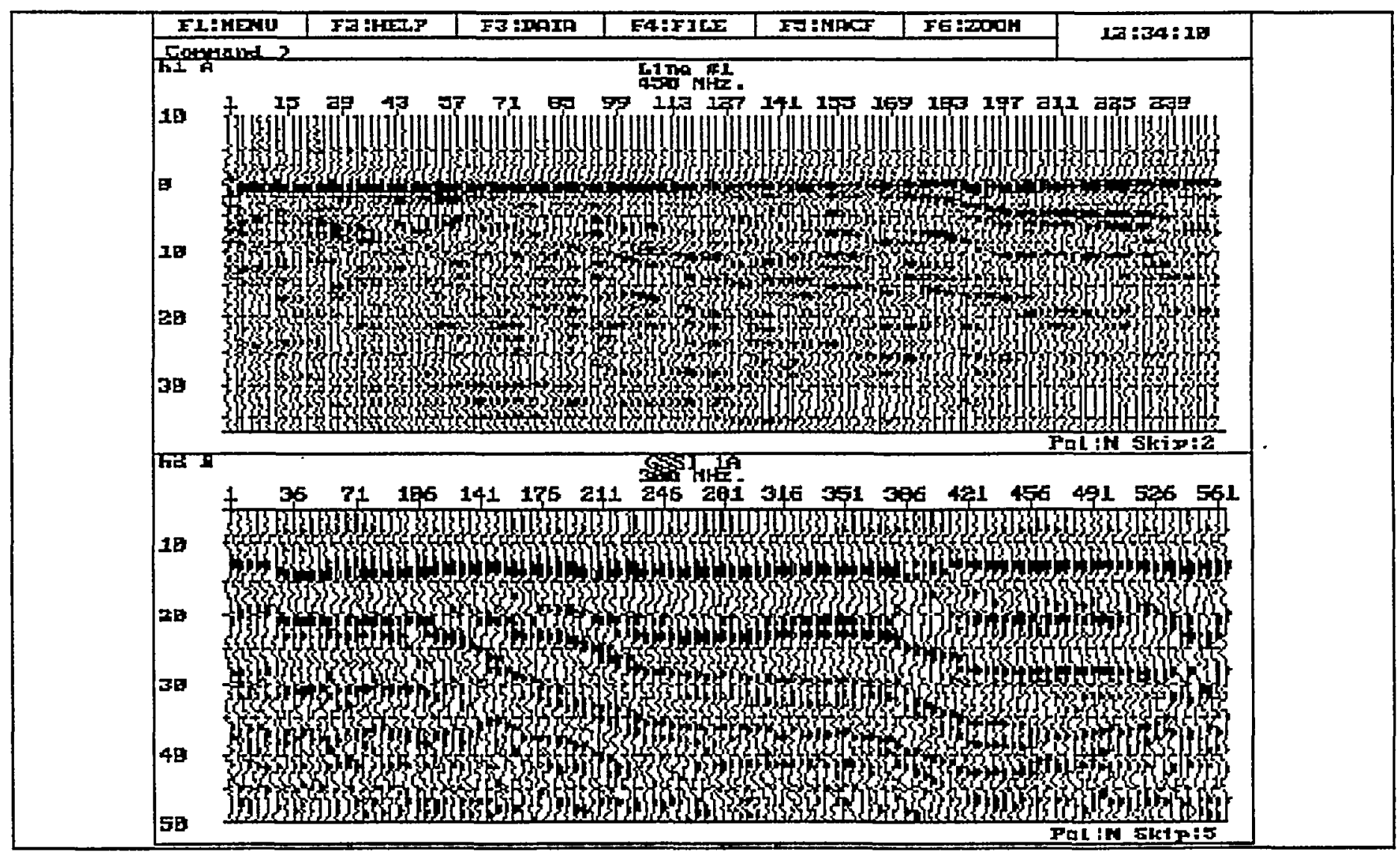

Comparison of Sensors \& Software $450 \mathrm{MHz}$. antenna and GSSI $300 \mathrm{MHz}$. antenna. Top S\&S, bottom GSSI. 
Good subsurface details can be seen in many of the plots with amplitude contrasts which could be indicative of moisture/clay content. The comparison between S\&S 450 $\mathrm{MHz}$. and GSSI $300 \mathrm{MHz}$ is as expected with the $300 \mathrm{MHz}$. penetrating deeper, but with slightly less resolution as compared to the $450 \mathrm{MHz}$. antenna.

\section{CONCLUSIONS}

The quality of the data recorded at Clay Cap Test Site was good. The data appears to show the clay being very susceptible to the orientation of the antennas. Ground contact by the antennas is critical, possibly more so in higher frequency antennas which were used on this project. 
TABLE \#1

CLAY CAP TEST SITE

TABLE OF COORDINATES, BEARINGS, AND DISTANCES

$\begin{array}{llcccc} & \text { LINE } & X & Y & \text { BEARING } & \text { DISTANCE LINE } \\ \text { FIGURE } & \text { NAME } & \text { EASTING } & \text { NORTHING } & \end{array}$

$\begin{array}{lllll}4 & 1 & \text { No site coordinates could be obtained for the } & 149 & 1 \\ 5 & 2 & \text { HP (Orange Balls) hence no site coordinates } & 149 & 2 \\ 6 & 3 & \text { can be computed for GPR lines. } & 149 & 3 \\ 7 & 4 & 149 & 4 \\ 8 & 5 & 6 & 149 & 5 \\ 9 & 7 & 149 & 6 \\ 10 & 8 & 149 & 7 \\ 11 & 9 & 149 & 8 \\ 12 & 10 & 149 & 9 \\ 13 & 11 & 149 & 10 \\ 14 & 12 & 149 & 11 \\ 15 & 13 & 149 & 12 \\ 16 & 14 & 149 & 13 \\ 17 & 15 & 16 & 149 & 14 \\ 18 & 1 \mathrm{~A} & 149 & 15 \\ 19 & 2 \mathrm{~A} . & 149 & 16 \\ 20 & & 149 & 1 \mathrm{~A} \\ 21 & & 149 & 2 \mathrm{~A}\end{array}$

TOTAL FOOTAGE IN SURVEY

2682

TEST FOOTAGE NOT SHOWN 443

PROJECT TOTAL FOOTAGE $\quad 3125$ 
Table 2

Acquisition and Processing Parameters

at the

Clay Cap Test Site

S\&S

Date Data Acquired Instrument Type Antenna Type Range

Pulse Voltage

Processing

Date Data Acquired Instrument Type Antenna Type Calibration Numbers

Post Processing Software

Range

Start Position

End Position

Survey Wheel

Scans/Foot

Samples/Scan

Transmit Pulse Rate

Vertical IIR Low Pass Filter Vertical IIR High Pass Filter Horizontal Low Pass Filter Processing
10/3/95

Pulse Ekko 1000

450 Bi-Static

Varied $50-100$ ns

200 Volts

Dewow, Dephase, AGC, Spiking

Decon, AGC, Fk Filter, Mean Filter

GSSI

10/3/95

GSSI (SIR 10) S/N 1158

$100 \mathrm{MHz}$ Mono-Static

Supplied by GSSI PG-90-177

Version 2.05

Max 141

Min 20

Diff 121

GSSI (RADANIII), SIS Vista GPR

250 ns

$-40 \mathrm{~ns}$

210 ns

131.06 ticks/foot

2

512

$50 \mathrm{Khz}$

$\mathrm{N}=2 \mathrm{~F}=50$

$\mathrm{N}=2 \mathrm{~F}=6$

$\mathrm{TC}=0$

Spiking Decon, AGC, Fk Filter, Mean

Filter 

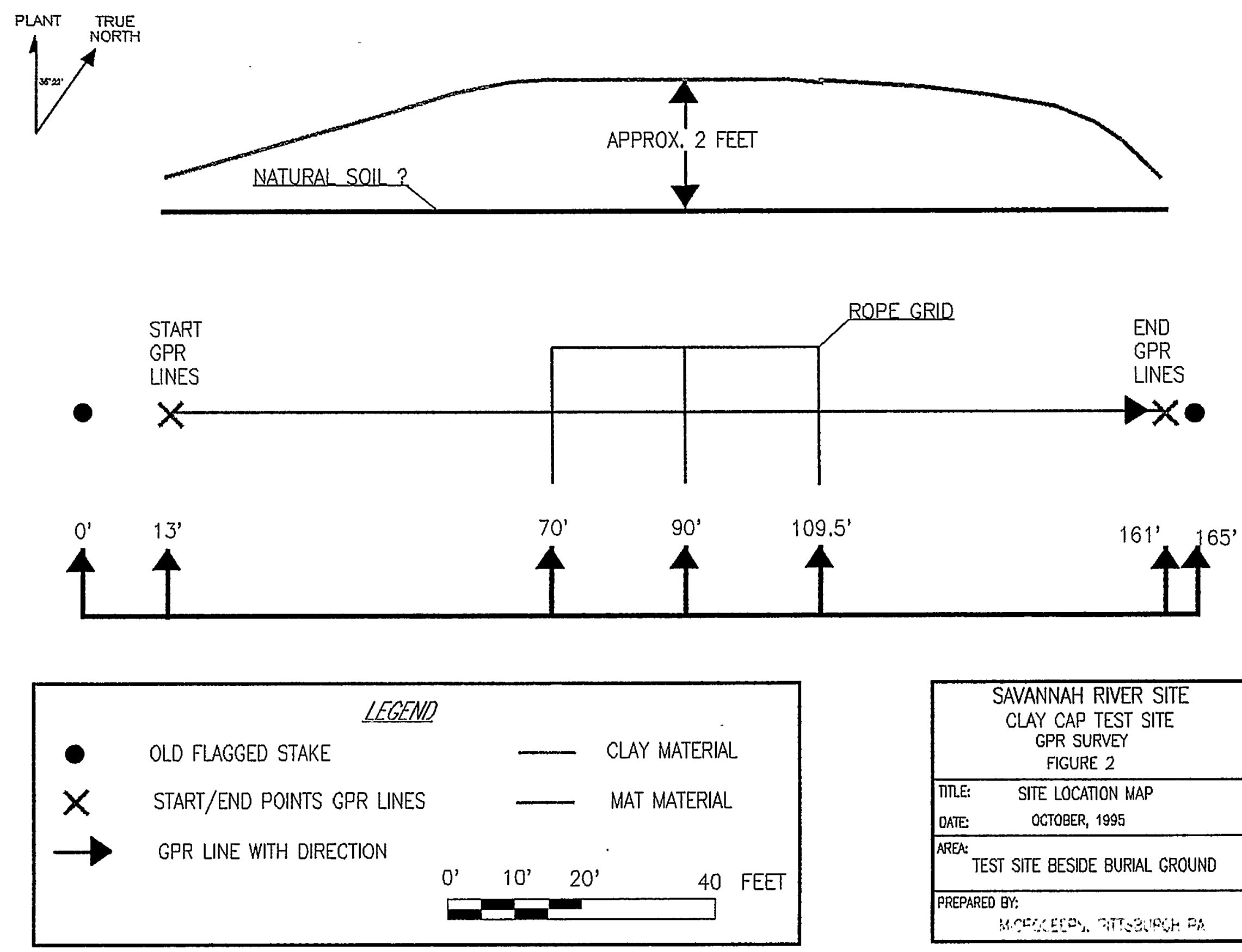

\begin{tabular}{|c|c|}
\hline & $\begin{array}{l}\text { SAVANNAH RIVER SITE } \\
\text { CLAY CAP TEST SITE } \\
\text { GPR SURVEY } \\
\text { FIGURE } 2\end{array}$ \\
\hline TILE: & SITE LOCATION MAP \\
\hline DATE: & OCTOBER, 1995 \\
\hline \multicolumn{2}{|c|}{ AREA: TEST SITE BESIDE BURIAL GROUND } \\
\hline & BY: \\
\hline
\end{tabular}




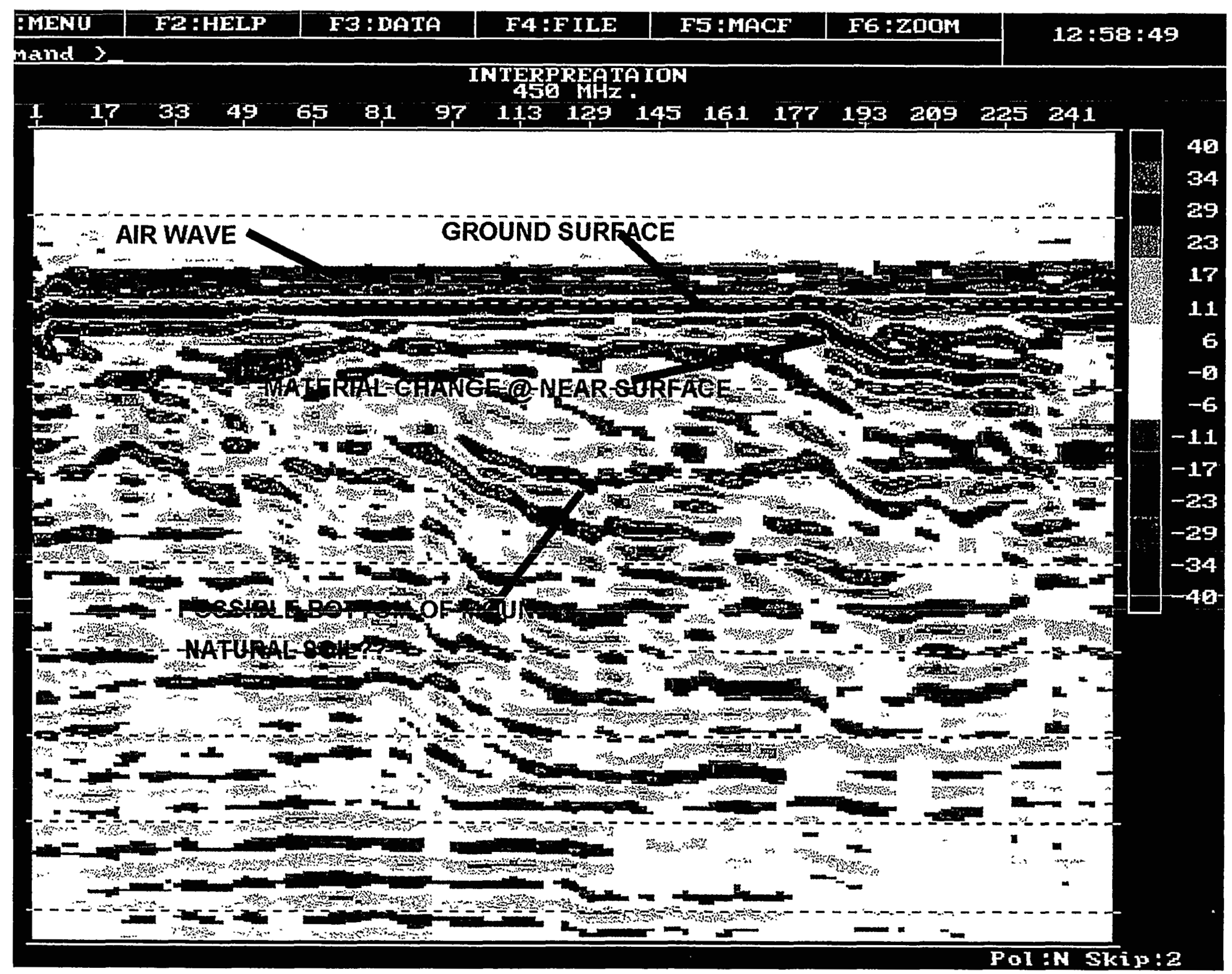




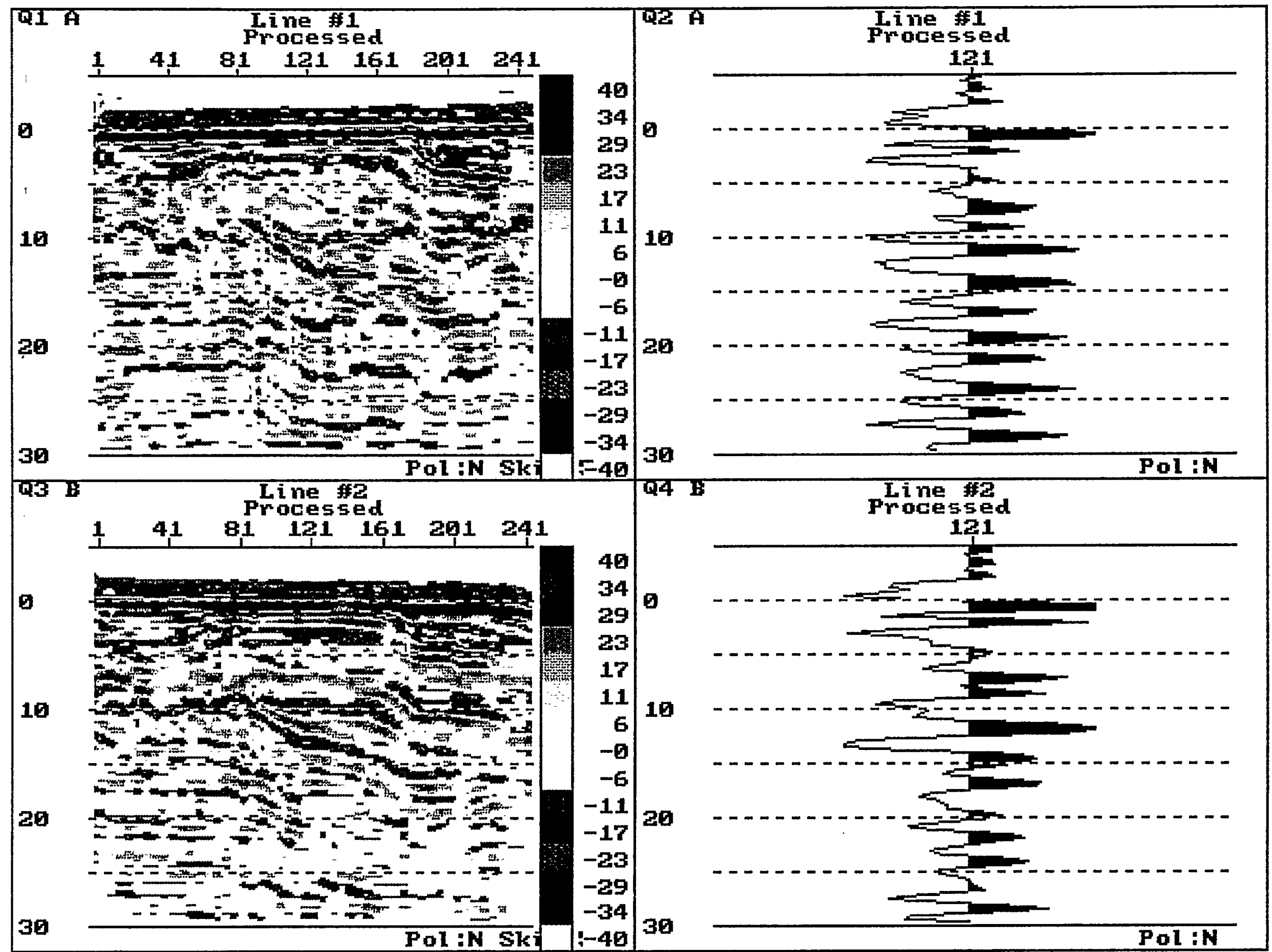




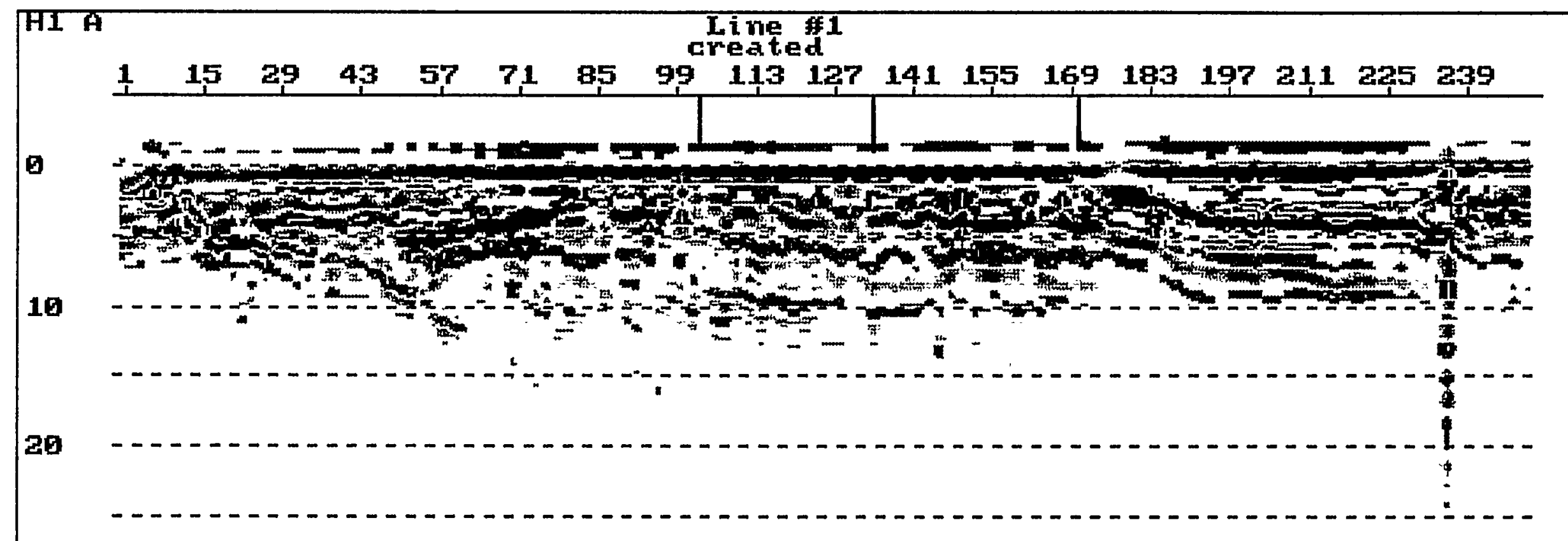

H

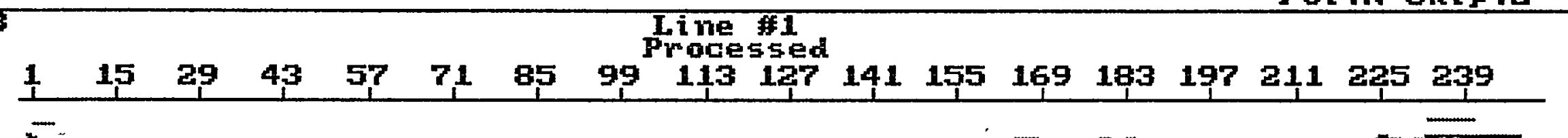

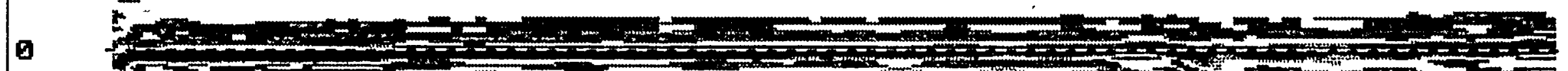

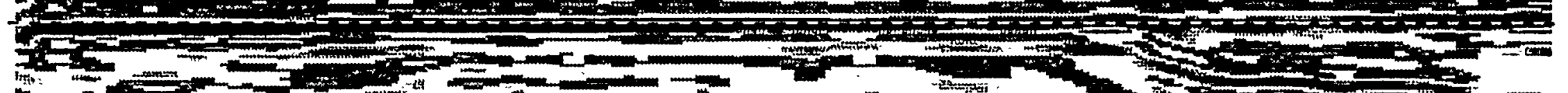

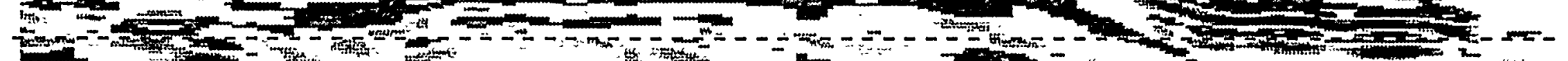

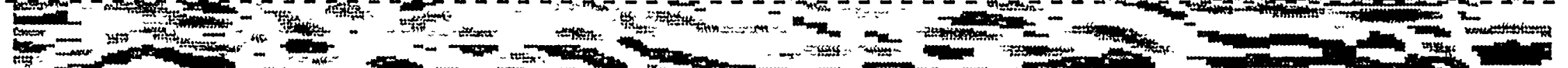

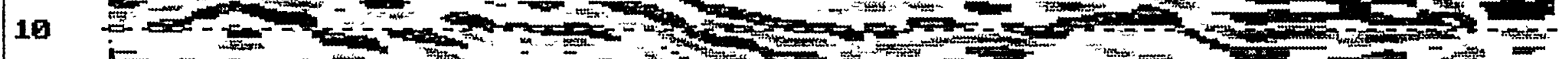

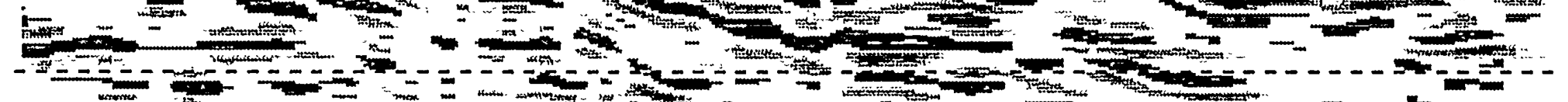

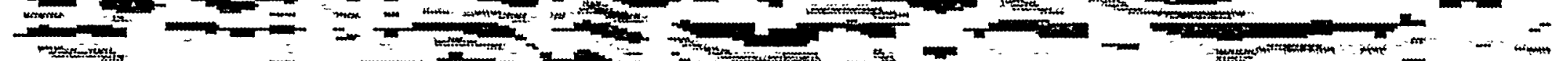

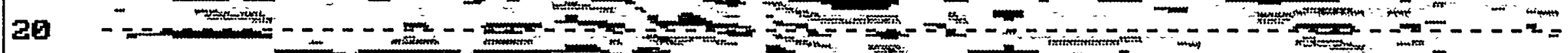
$-I_{-1}=-1-1-1$

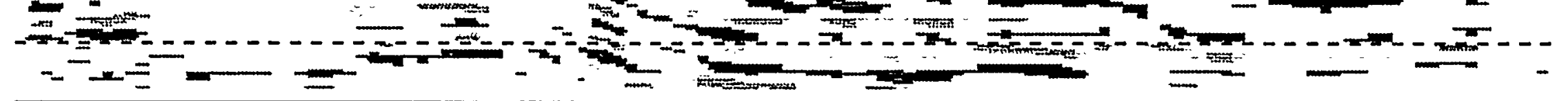




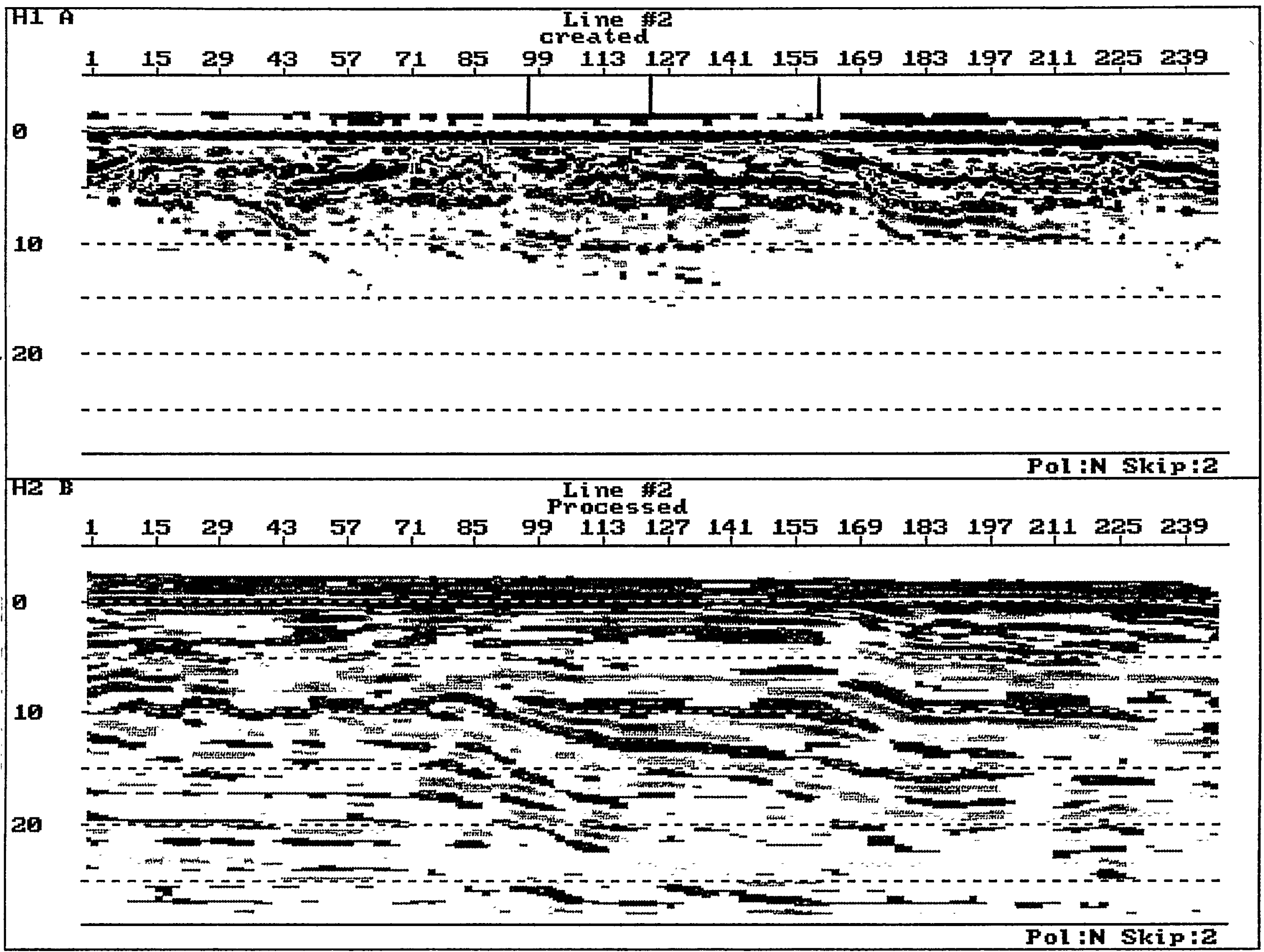




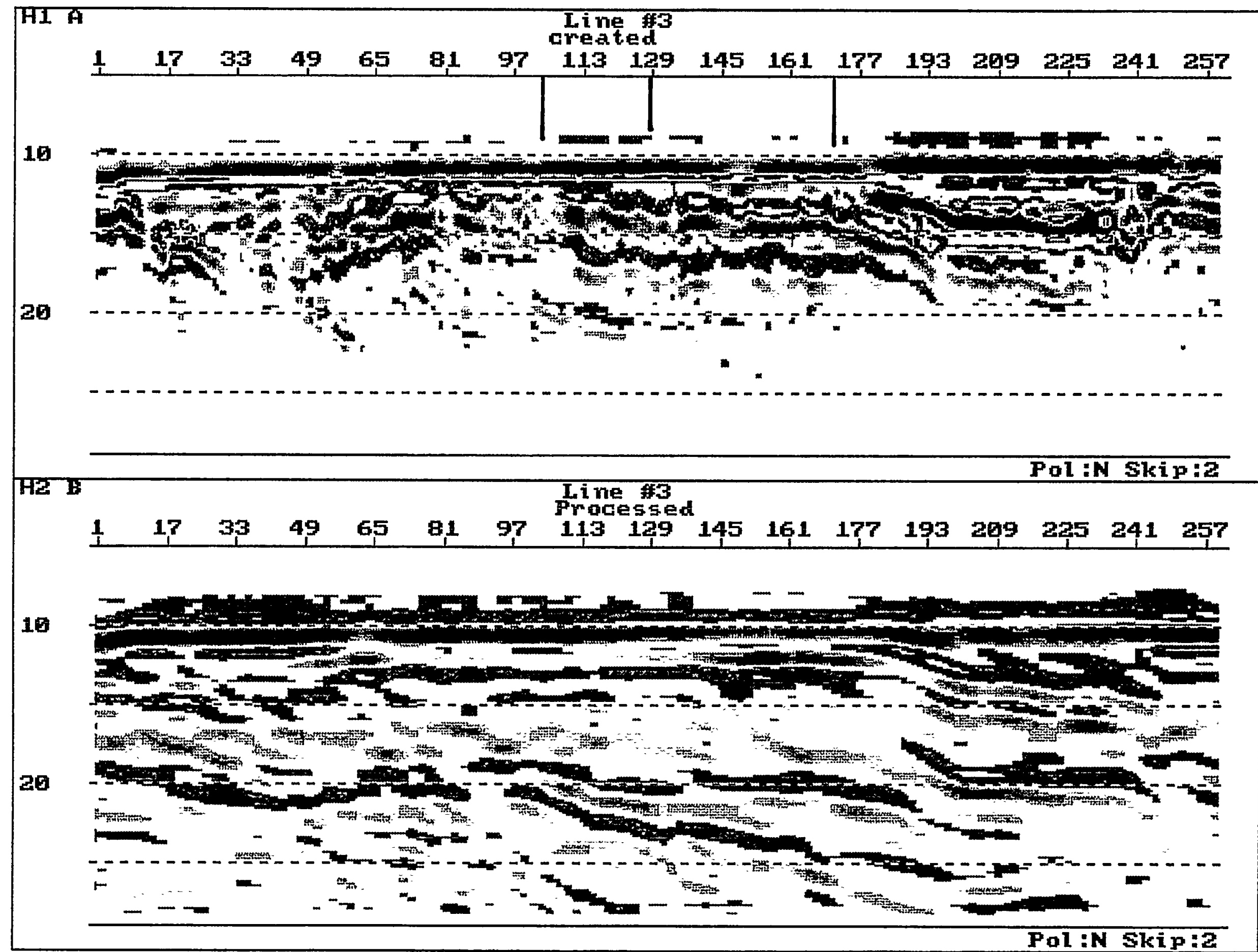




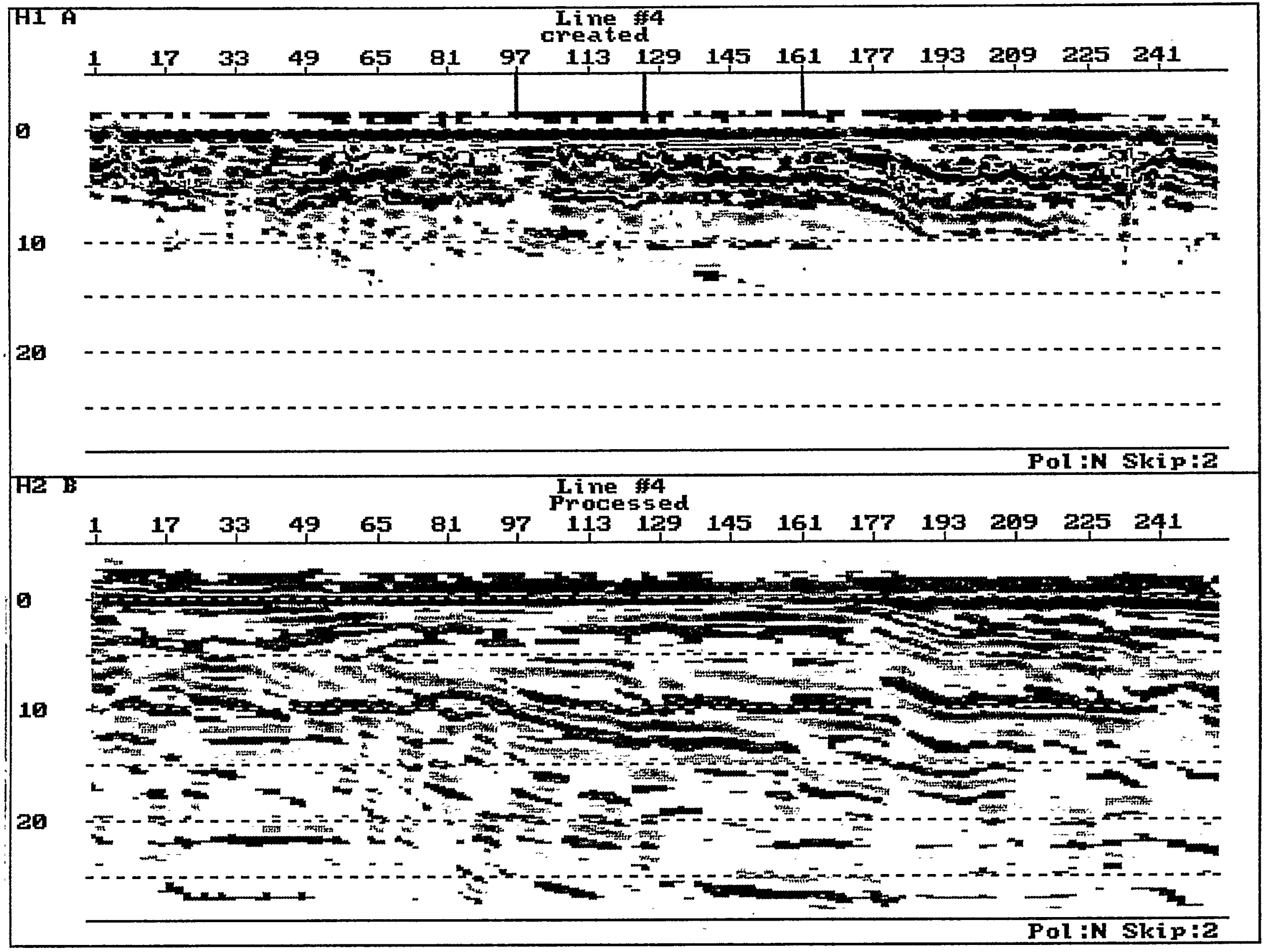




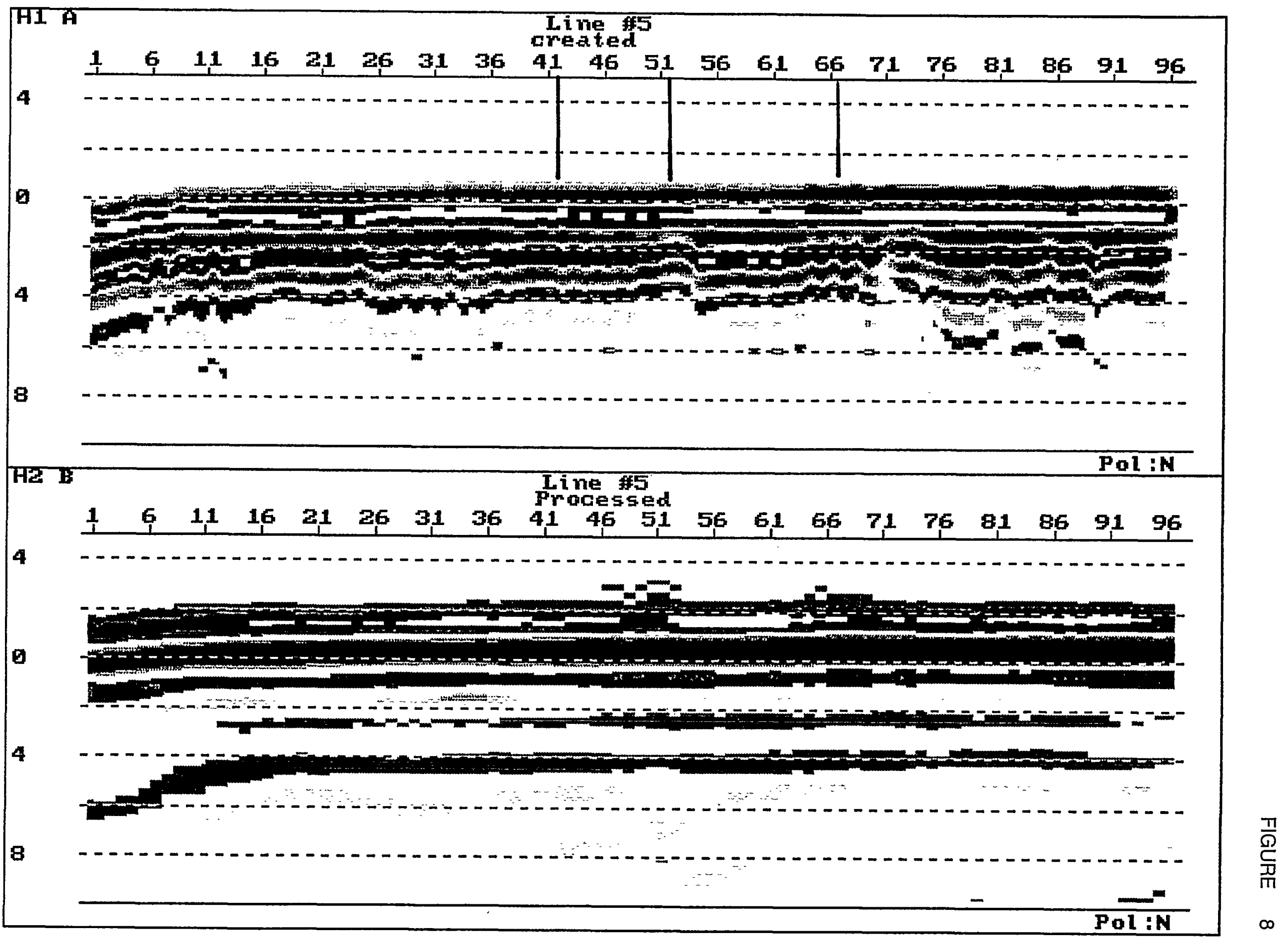




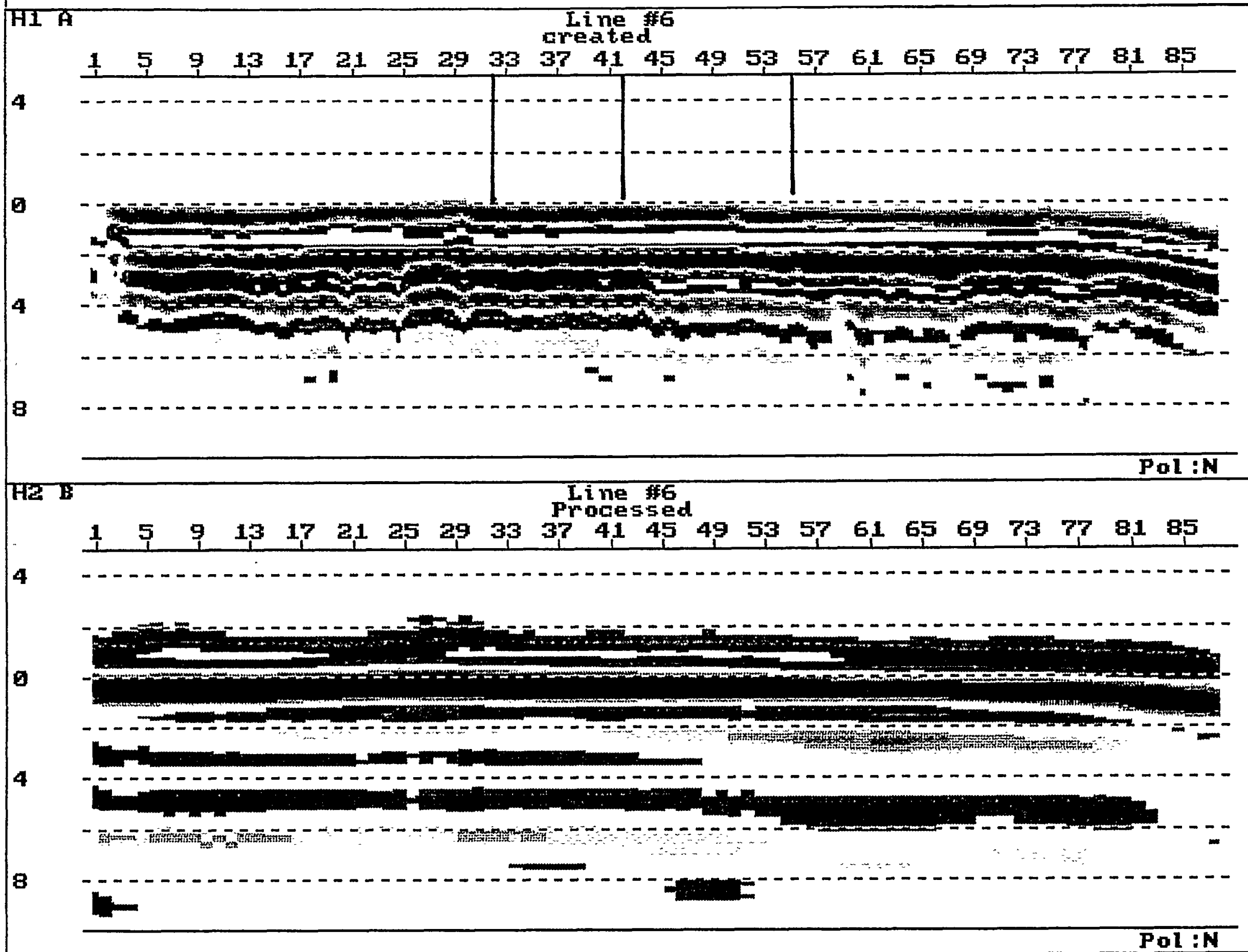




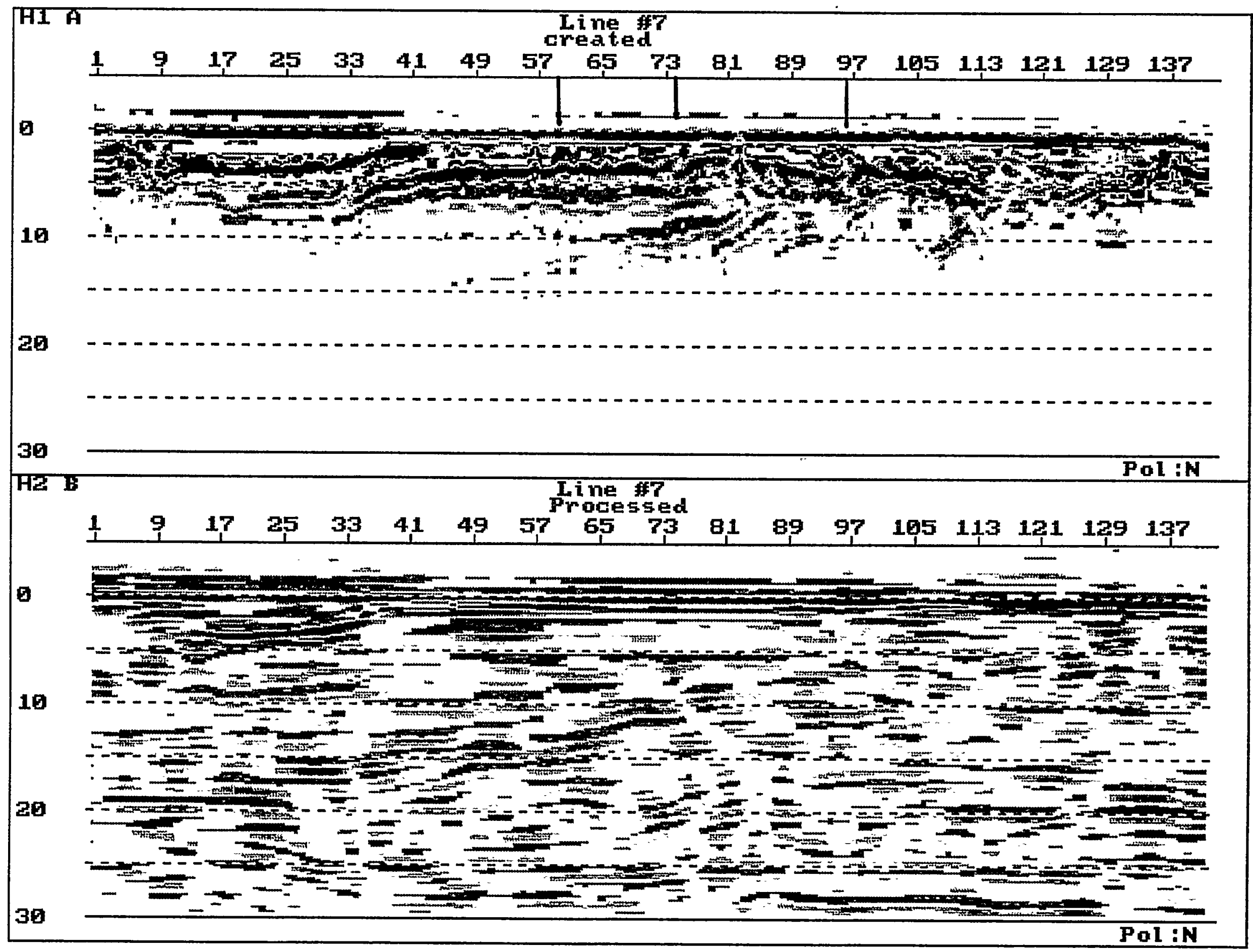




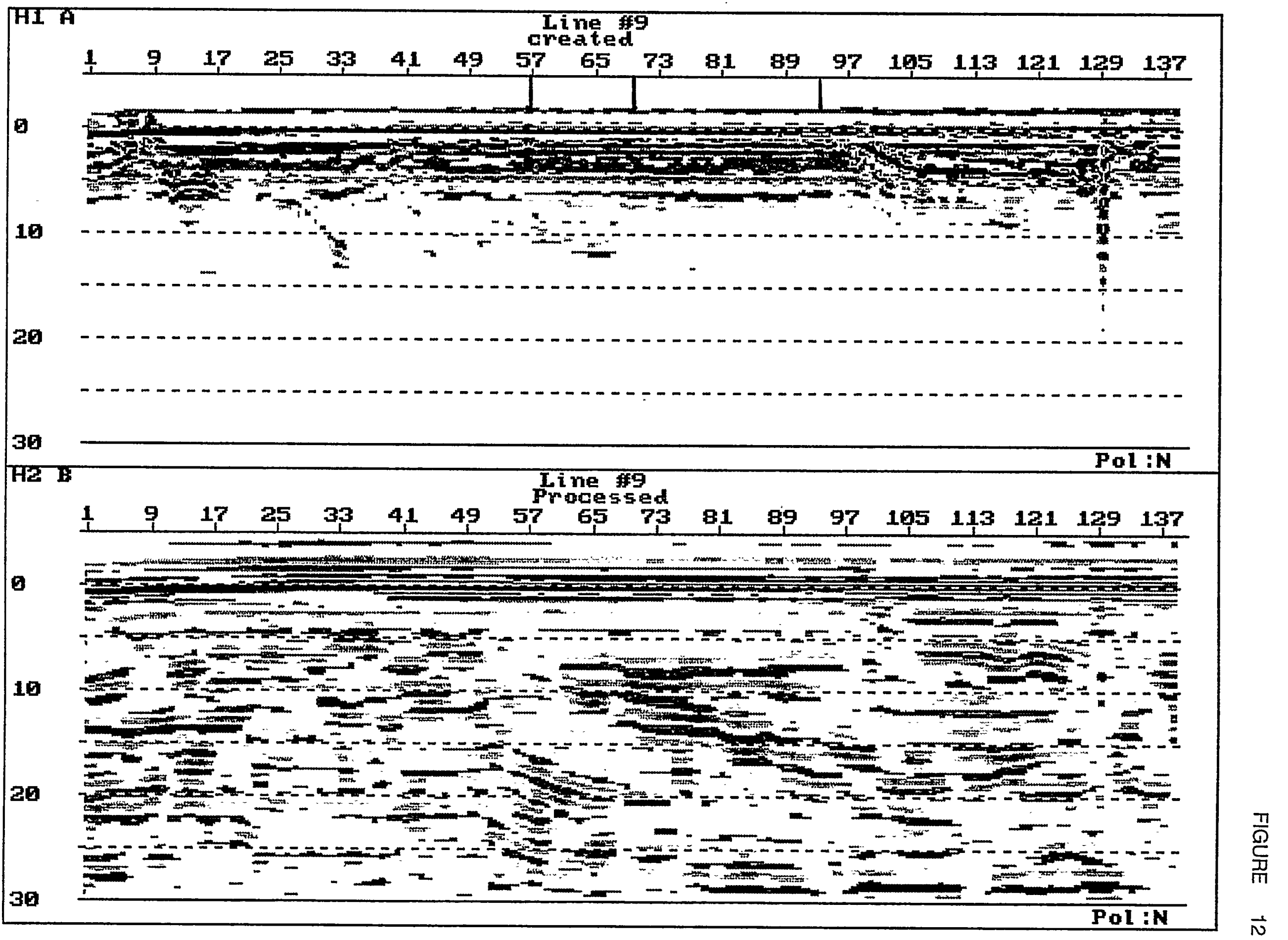




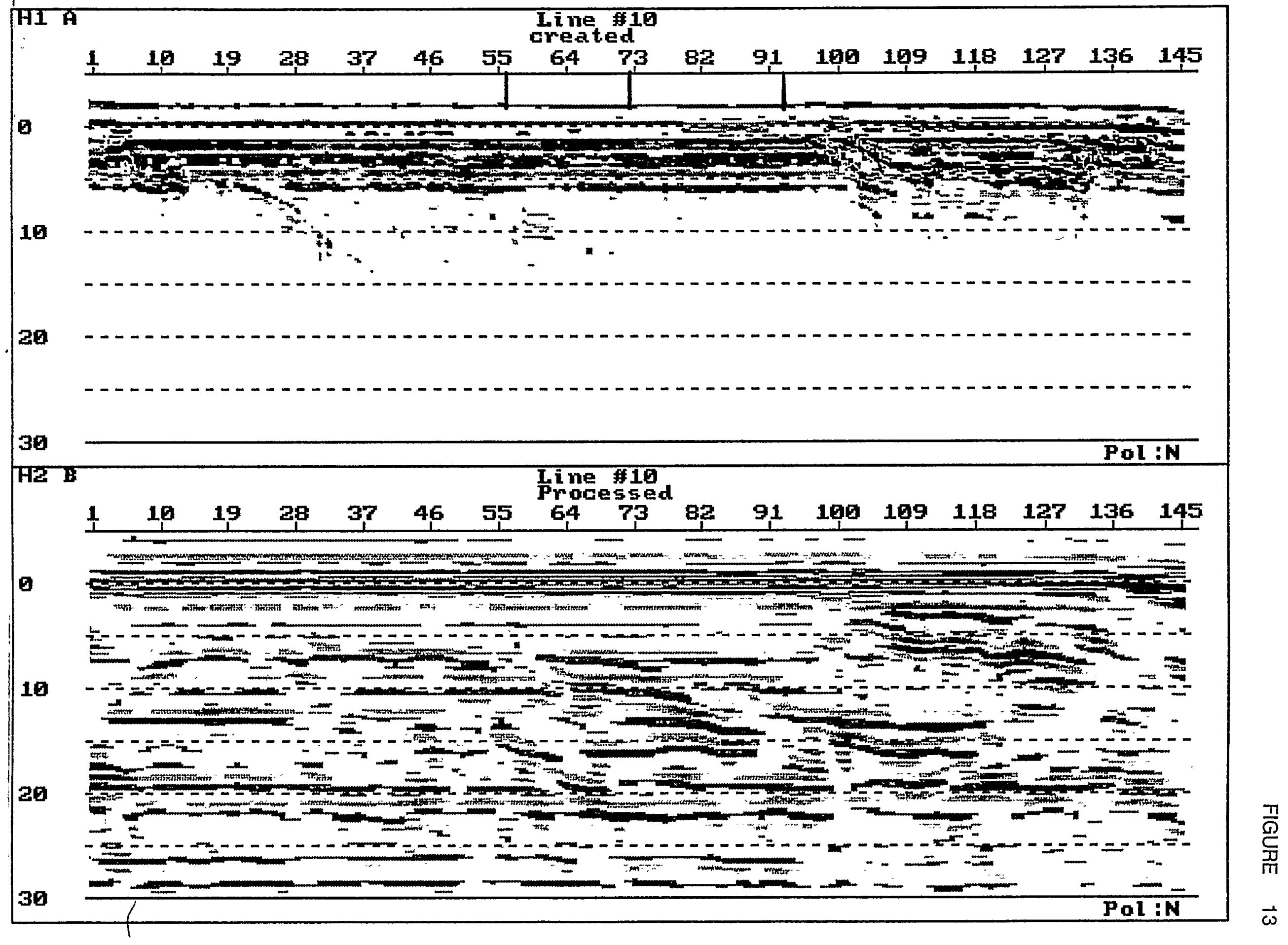




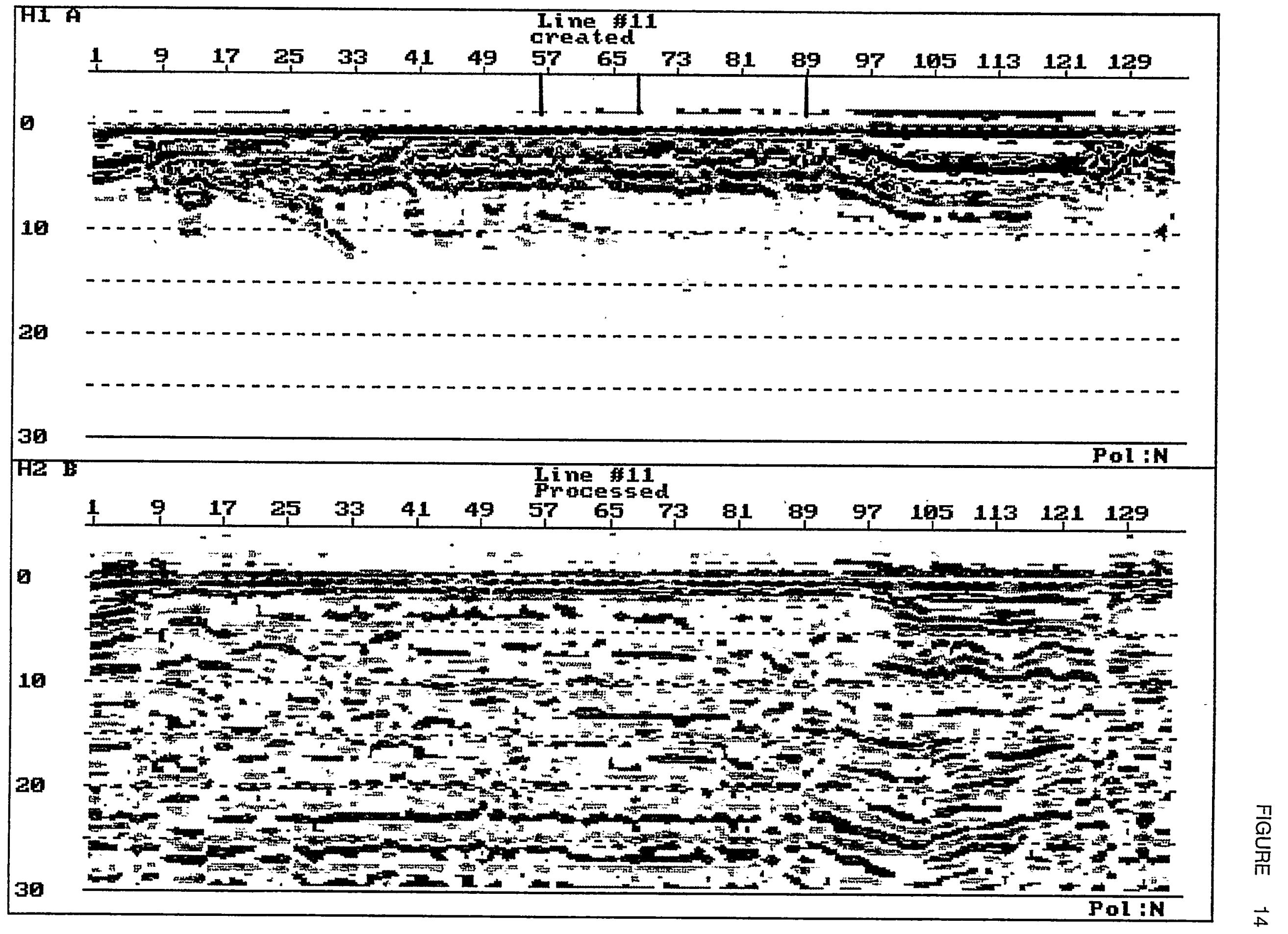




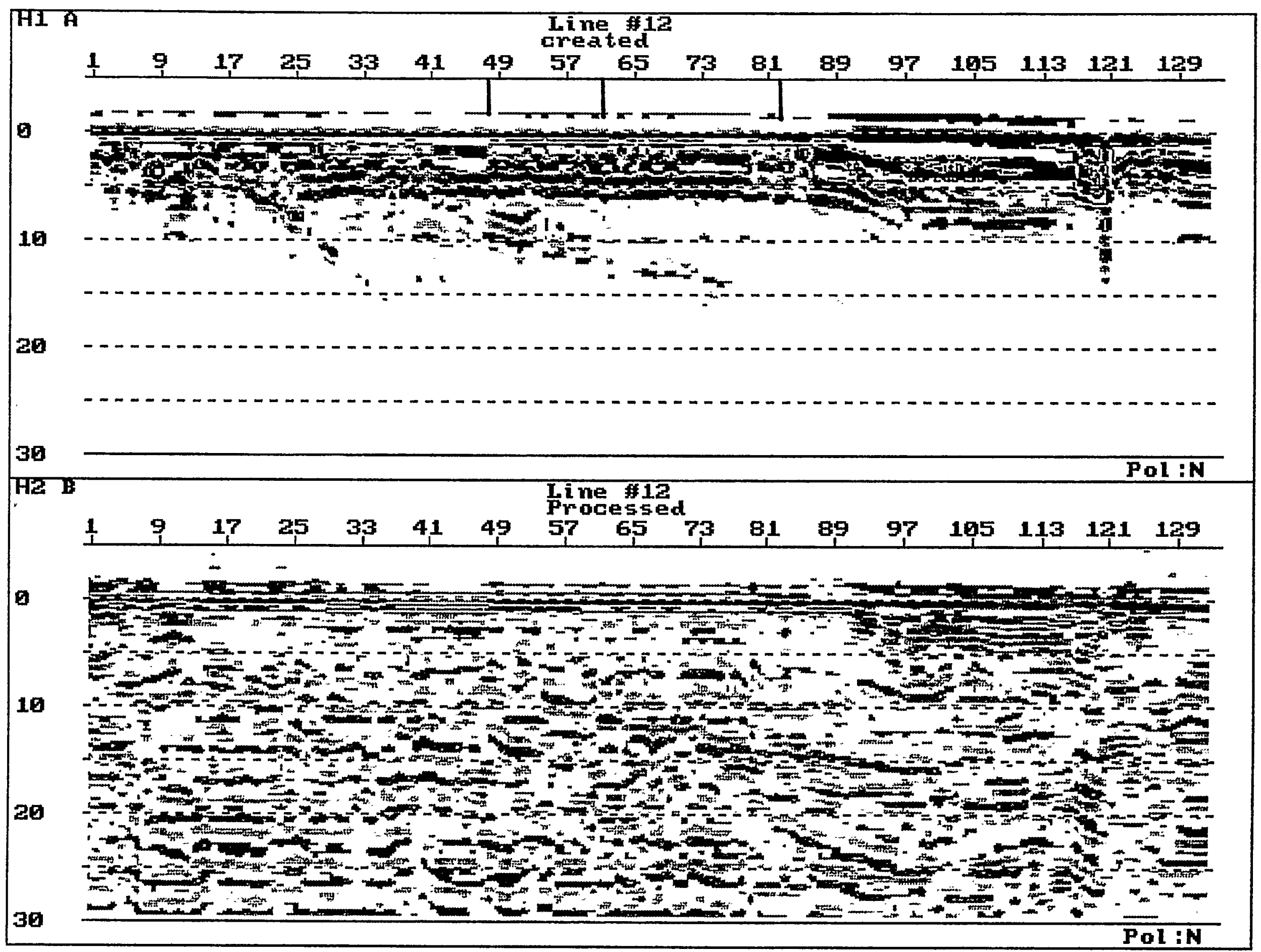




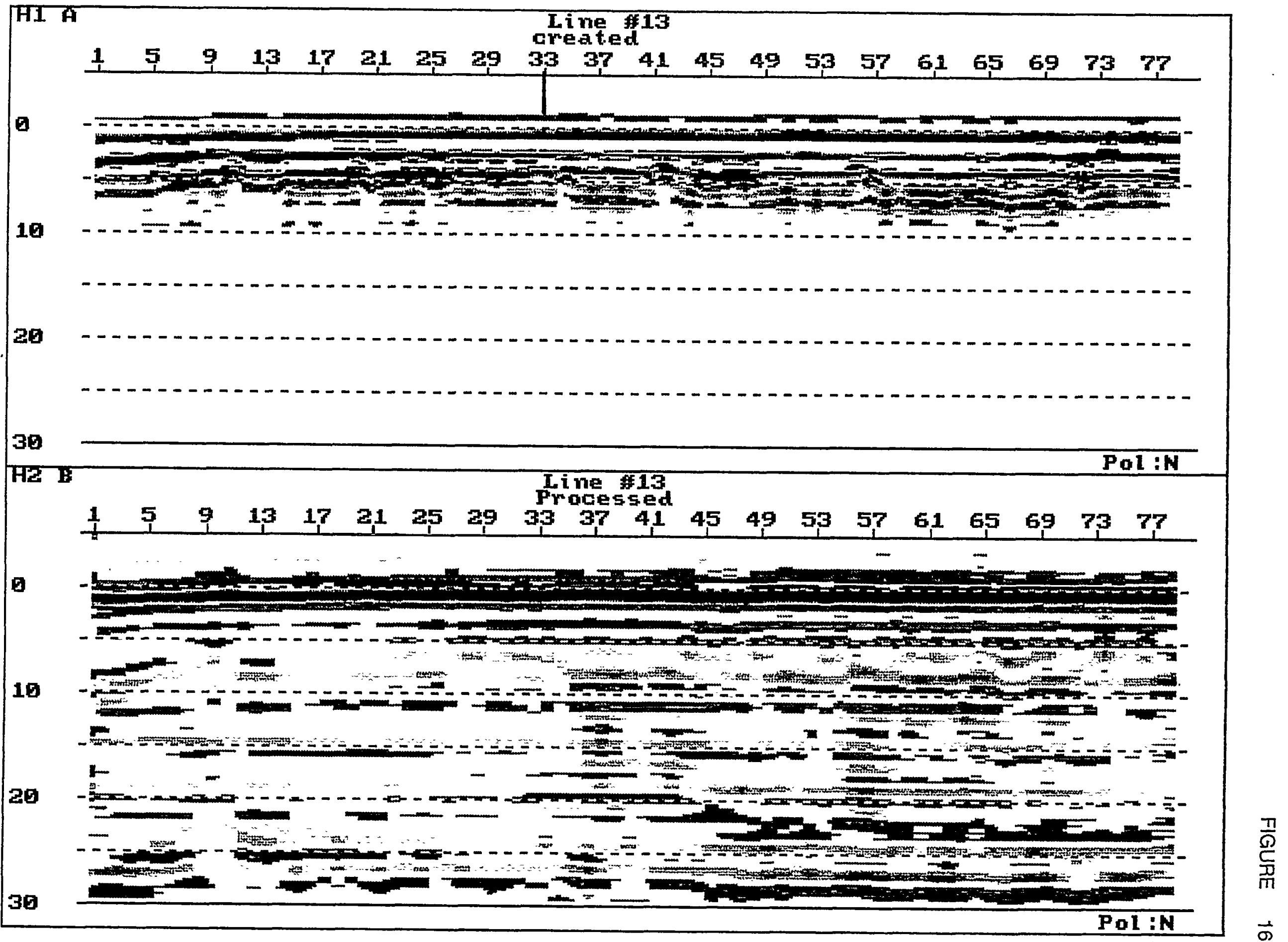




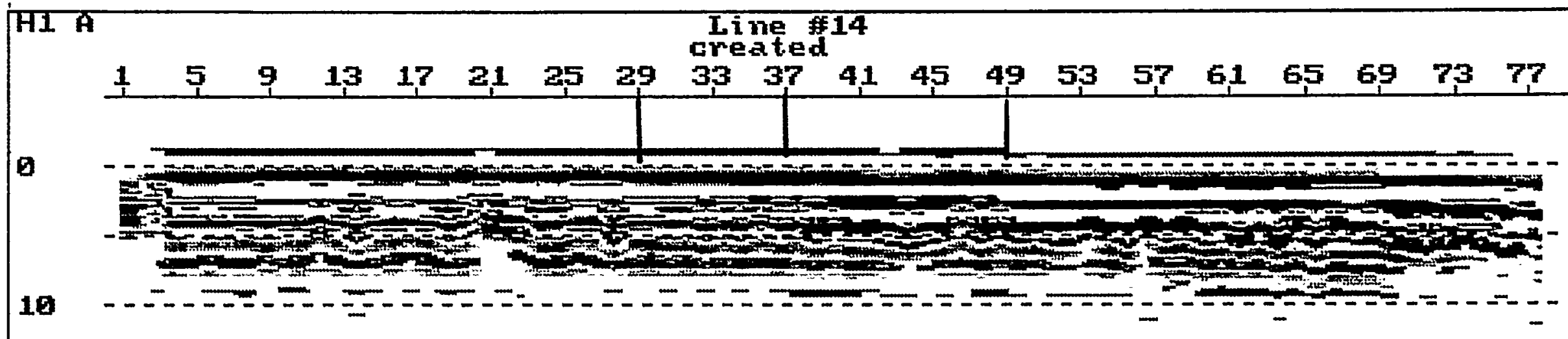

20

30

HE B

Iine f14

Processed

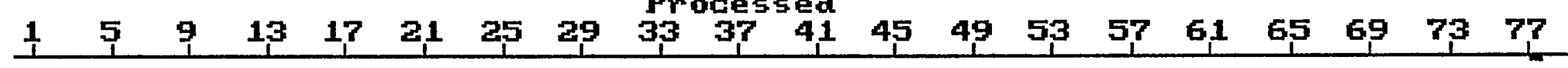

a

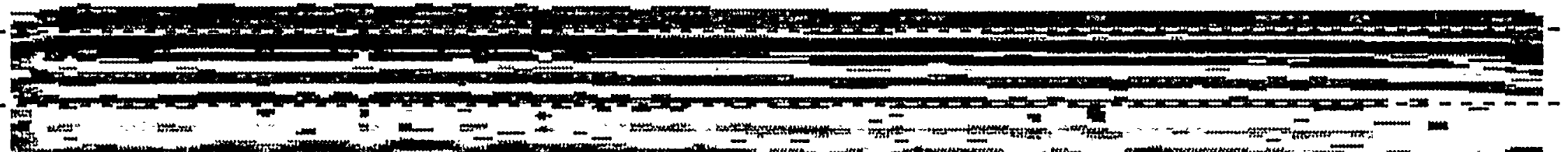

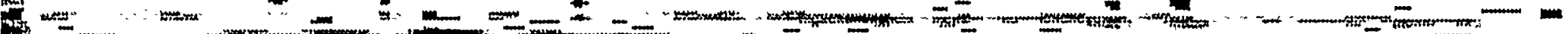

10

(1) (19) 19-1 -

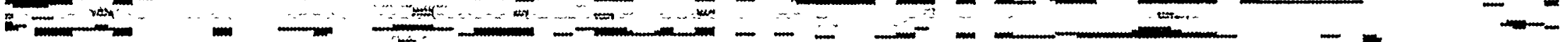

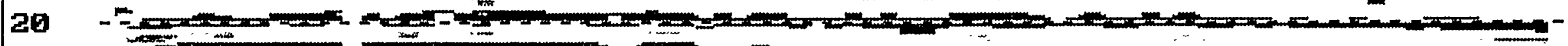

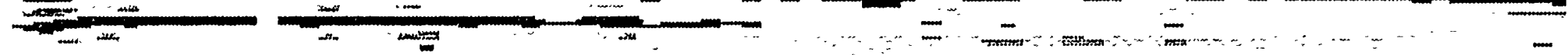
rim $-\infty-20$ 


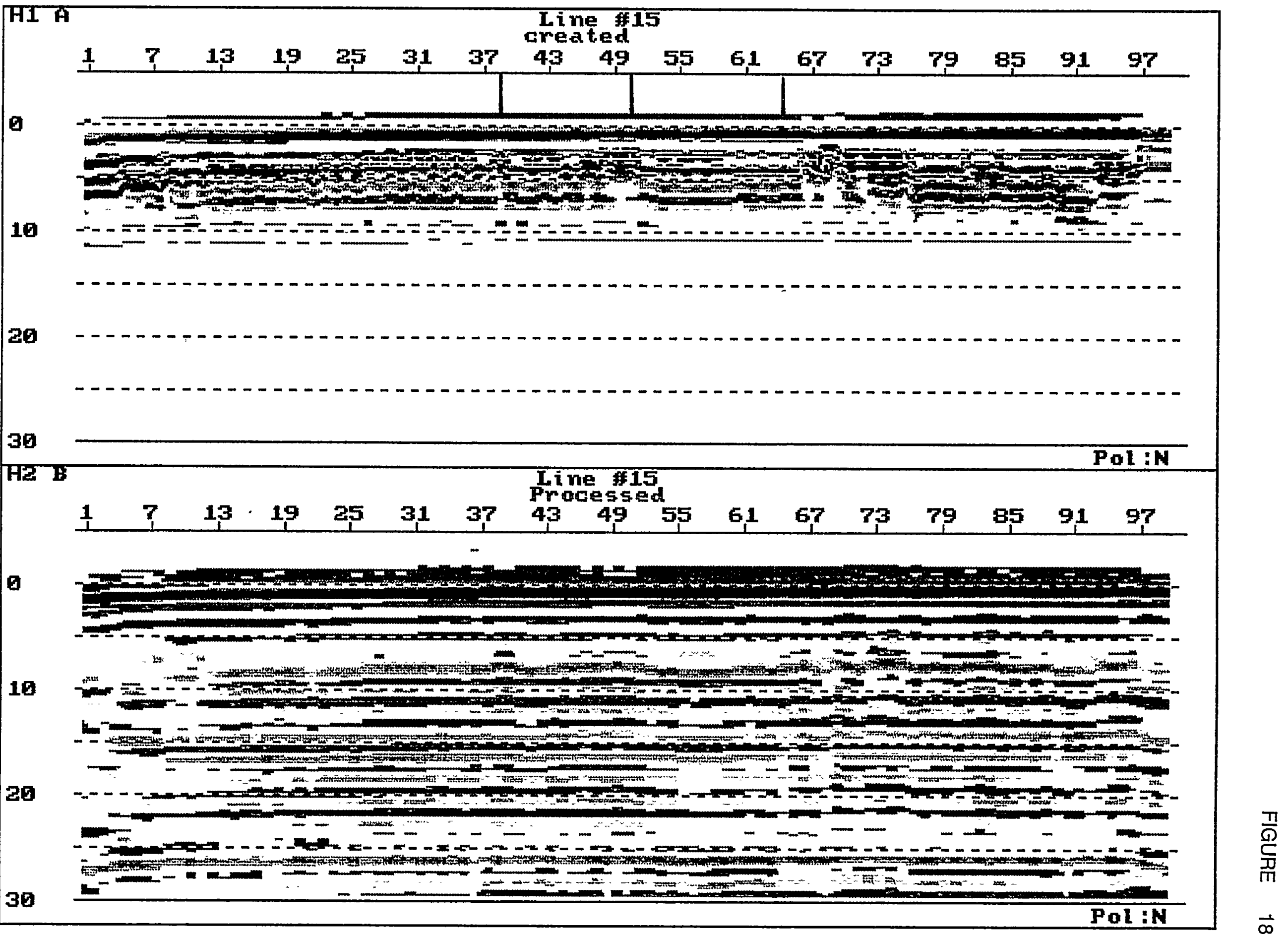




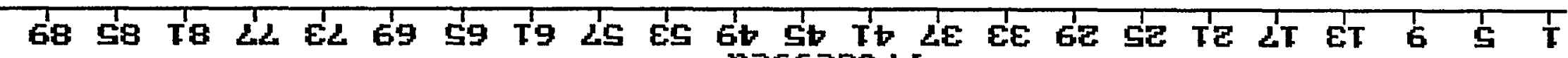 Passagoud}

N: 10d

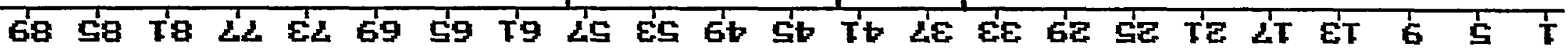
pIfyux 


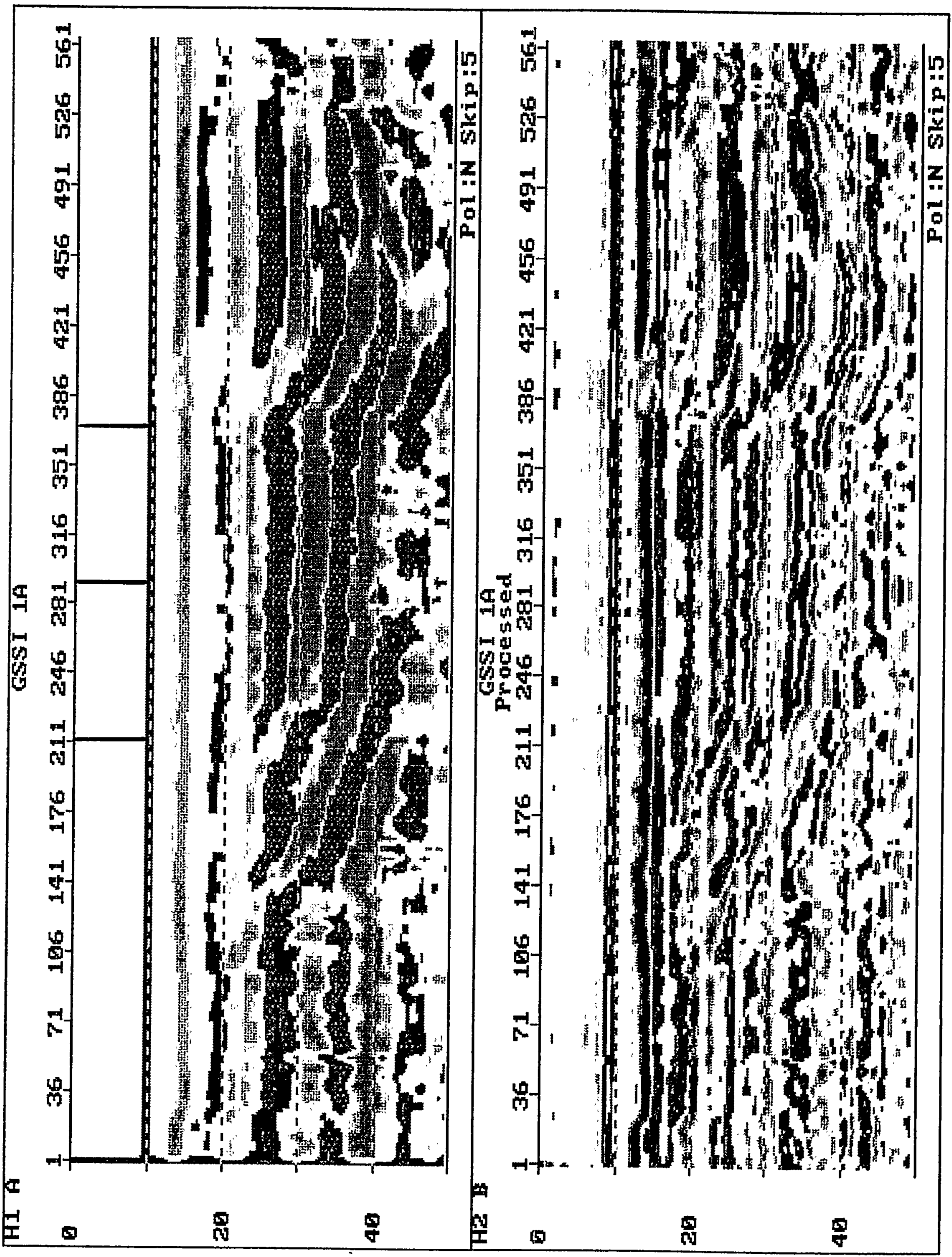




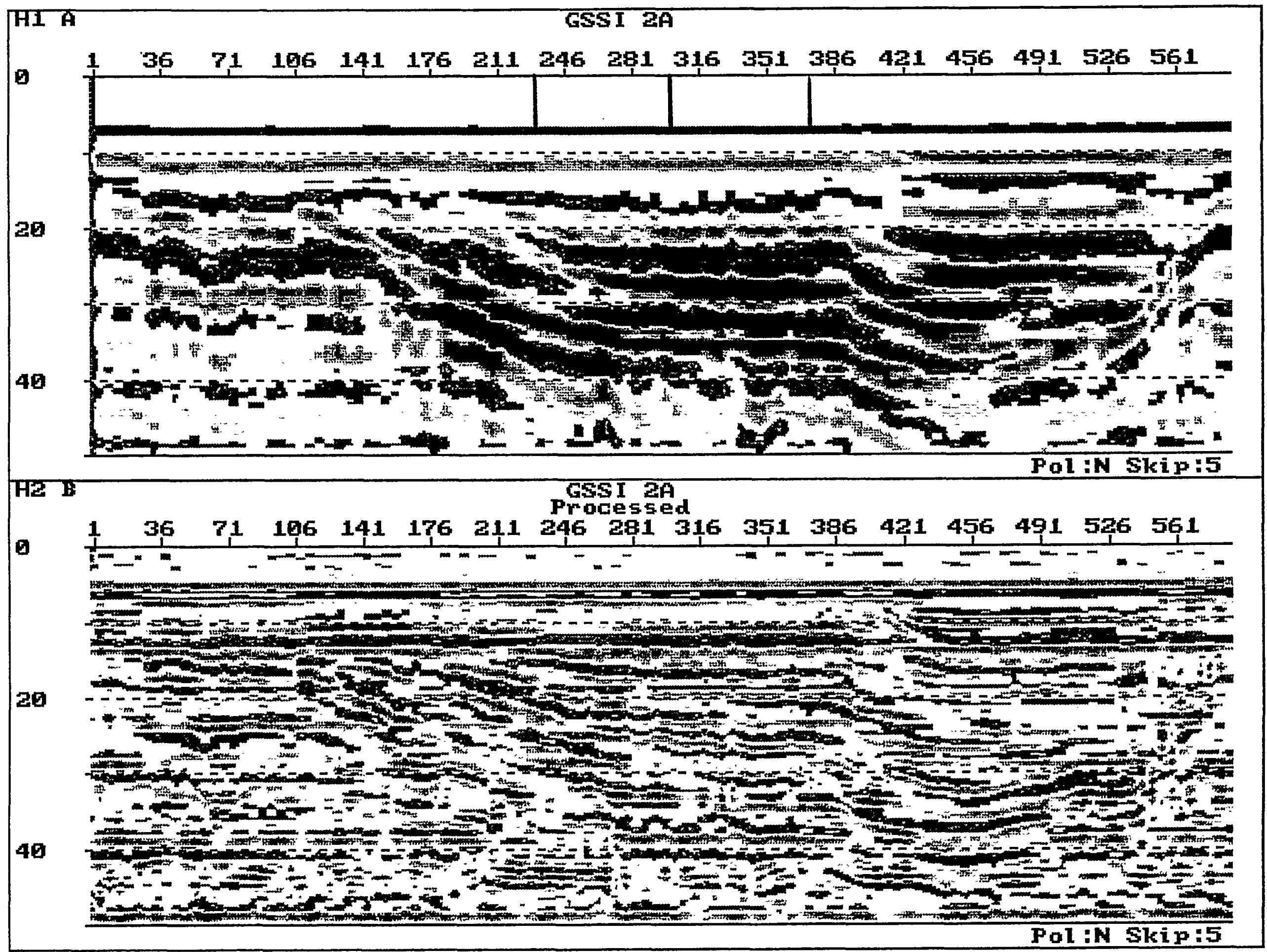


MICROSEEPS APR FIELD LOG

JoB: CLAY TEST PIt

TERRAIN:

TAPE NUMBER: $5: \$ S$ PE $1000 *$ SCANS/FT

TICKS/FT:

RANGE NS:

ANT. MHZ
DATE: $\quad 10-3-95$

WEATHER:

FILTERS:L:N: FREQ

VERT. HiN: FREQ:

HORIZ. LP: (TC)

SAMPLES/SCAN:

START NS:

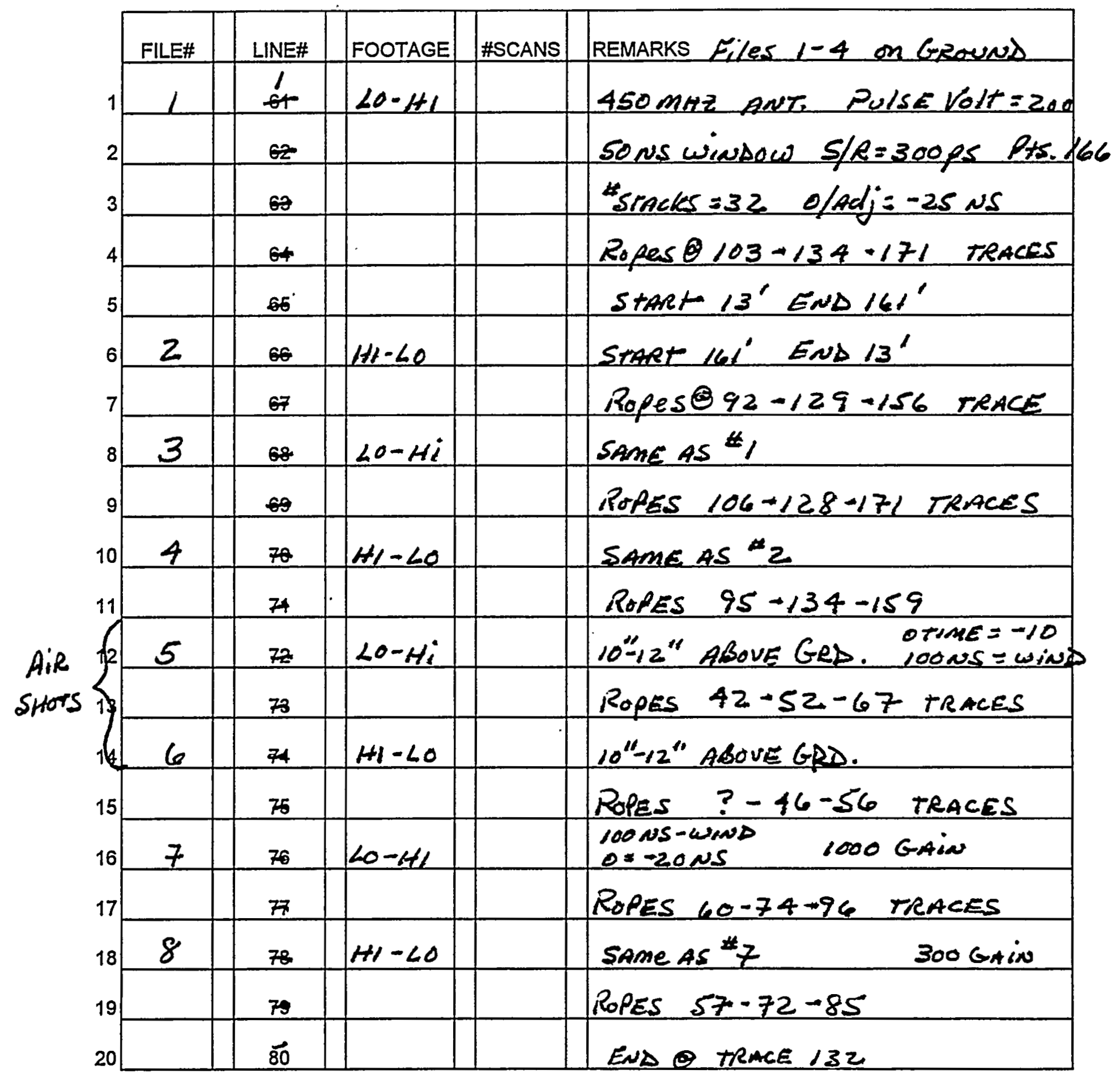

PAGE_ 1 OF_ 2 
JOB: CLAY TEST PIT

TERRAIN:

TAPE NUMBER:

SCANS/FT:

TICKS/FT:

RANGE NS:

ANT. MHZ.
-DATE: $10 \cdot 3-95$

WEATHER:

FILTERS:L:N: FREQ:

VERT. H:N: FREQ:

HORIZ. LP: (TC)

SAMPLES/SCAN:

START NS:

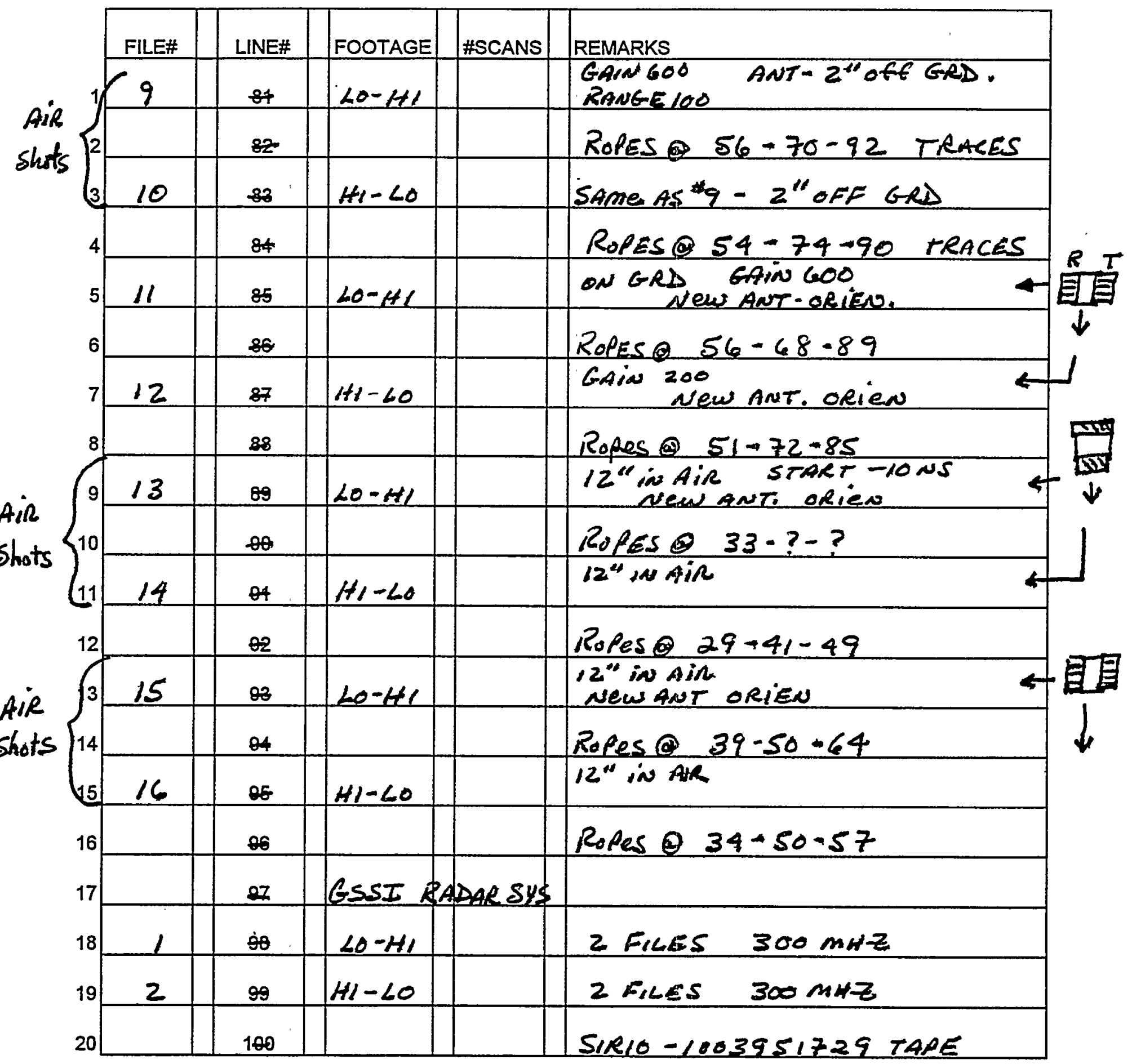

PAGE 2 OF 2 
